\title{
1 High permeability of the CSF flow in the juvenile mouse brain by
}

\section{brain-wide DCE-MRI}

6 Yayoi Wada ${ }^{1,2,6}$, Hirohiko Imai ${ }^{3,6}$, Yuki Yamawaki ${ }^{1,6}$, Md Sorwer Alam Parvez $^{4}$, Sae Matsui ${ }^{1,5}$, and

7 Gen Ohtsuki ${ }^{1,6,7}$

$8{ }^{1}$ Department of Drug Discovery Medicine, Kyoto University Graduate School of Medicine, 53

9 Shogoin-Kawahara-cho, Sakyo-ward, Kyoto 606-8397, Japan

$10{ }^{2}$ Laboratory of Genetics, Kyoto University Graduate School of Biostudies, Yoshida-Shimoadachi-

11 cho, Sakyo-ward, Kyoto 606-8501, Japan

$12{ }^{3}$ Department of Systems Science, Kyoto University Graduate School of Informatics, Yoshida-

13 Honmachi, Sakyo-ward, Kyoto 606-8501, Japan

$14{ }^{4}$ Department of Genetic Engineering \& Biotechnology, Shahjalal University of Science \&

15 Technology, Sylhet, 3114, Bangladesh

$16{ }^{5}$ Department of Science, Kyoto University, Kyoto, Japan

$17{ }^{6}$ These authors contributed equally.

$18{ }^{7}$ Submitting and Communicating Author

$20 *$ For correspondence:

21 Gen Ohtsuki, Ph.D.

22 Kyoto University Graduate School of Medicine, Medical Innovation Center, 53 Shogoin Kawahara-cho,

23 Sakyo-ward, Kyoto 606-8507, Japan

24 Tel: $+81(0) 753667477$

25 Fax: +81(0)75 7621884

26 E-mail: ohtsuki.gen.7w@kyoto-u.ac.jp 


\section{Abstract}

29 The vasculature system with a lymphatic function in the brain is manifested as meningeal lymphatic

30 vessels and the glymphatic system, which drain waste products from cerebrospinal fluid (CSF) and

31 produce interstitial fluid. Invasion of stimulated immune cells or inflammatory cytokines during the

32 maturation is regarded as a sign of the disruption of brain functions through excessive immune

33 stresses. However, it is unclear when the lymphatic system is functionally completed and in which

34 parts of the organ the brain immunity is privileged (i.e., the blood-brain barrier is fully established).

35 Here, we visualized the whole-head signal of gadolinium $(\mathrm{Gd})$ contrast agents in mouse brains to

36 investigate the CSF flow from the signals of Gd-contrast agents using magnetic resonance imaging

37 (MRI) in the course of developmental stages. We found higher Gd-signals in the olfactory bulbs,

38 prefrontal cortex, parietal surface regions of the neocortex along with dorsal meningeal lymphatic

39 vessels, ventral midbrain, and a part of cerebellum, as well as in the basal brain regions, at the

40 immature stage of postnatal (P) 4 weeks, compared to the P8-12 weeks. Our results suggest that the

41 barrier of the vasculature system in mouse brains is still permeable until P1-month and small

42 molecules can leak into the parenchyma.

43

44 


\section{Introduction}

46 The blood-brain barrier (BBB) is a sophisticated endothelial barrier that controls the milieu of the

47 brain and prevents the extravasation of fluids, solutes, inflammatory cytokines, microbial pathogens,

48 blood- and immune-cells from the blood flow, as an immune privilege. At the BBB, the water

49 component of cerebrospinal fluid (CSF) dominantly crosses the astrocytic water channels AQP-4

50 (Nielsen et al., 1997), and the solutes enter the brain parenchyma via astrocytic transporters or ion

51 channels. At the paravascular space between the basement membrane of smooth muscle cells and

52 glia limitans, the CSF infiltrates into the brain parenchyma as the interstitial fluid (ISF), which drives

53 the removal of waste products, gasses, and extracellular solutes of the parenchyma (Iliff et al., 2012,

54 2013; Louveau et al., 2017). According to Kiviniemi et al. (2016), cardiac pulsation ( 1.1 Hz),

55 respiratory pulsation $(\sim 0.4 \mathrm{~Hz})$, and very low-frequency vasomotor pulsations $(<0.01 \mathrm{~Hz})$

56 (Kiviniemi et al., 2016) drive CSF/ISF exchanges. The BBB is formed during embryogenesis in the

57 murine but might not be completely impermeable to solutes and cells during the postnatal period.

58 After birth, the junction of BBB matures very rapidly, and they are thought to attain their adult

59 characteristics (Bauer H et al., 1995; Bauer HC et al., 2014). However, it is unclear when the

60 permeability barrier is functionally completed, how CSF leakage to the parenchyma is regulated in

61 the course of brain maturation, and if there are differences of the permeability depending on brain

62 regions.

A principal function of CSF is to provide a constant fluid flow to maintain homeostasis in the

64 ventricular system and on the surface of the brain by carrying lots of secreted mediators, solutes, and

65 immune cells and excreting the waste products of the parenchyma. The CSF is also able to transmit

66 hormones, transmitters, inflammatory cytokines, and even exosomes (Brown et al., 2004; Praetorius,

67 2007; Yagi et al., 2017; Lepennetier et al., 2019). The CSF is produced by the ependymal cells in the

68 choroid plexus of all the ventricles: lateral, third, and fourth ventricles. The entire CSF volume and

69 production rate had been estimated at $35 \mu \mathrm{l}$ and is $0.32 \mu \mathrm{L} / \mathrm{min}$, respectively, in the mouse brain 
70 (Pardridge, 2016). While CSF is produced in the choroid plexus with a rich capillary bed, the

71 osmotic pressure of the CSF is normally around $5 \mathrm{mOsm} / \mathrm{kg}$ higher than that of the serum and the

72 blood plasma (Cserr, 1971; Brown et al., 2004; Praetorius, 2007). According to Akaishi et al. (2020),

73 the CSF osmolarity is $289.5 \pm 6.6 \mathrm{mOsm} / \mathrm{kg}$ while the serum osmolarity is $283.6 \pm 6.6 \mathrm{mOsm} / \mathrm{kg}$,

74 implying that the passive osmotic pressure contributes to the CSF flow, as well as the pulsatile does.

75 A recent direct measurement with less leakage of the CSF production from lateral ventricles

76 indicated lower production volume of $108.0 \pm 7.6 \mathrm{~nL} / \mathrm{min}$ and $83.9 \pm 2.8 \mathrm{~nL} / \mathrm{min}$ in 2-month-old

77 male and female C57BL/6 mice, respectively (Liu et al., 2020). Previous research by Kress et al.

78 (2014) showed that the efficiency of exchange between the subarachnoid CSF and the brain

79 parenchyma is higher at least in young 2-month-old mice than in the aged group. The study

80 demonstrated the decline of the CSF/ISF exchange in the course of maturation using in vivo and ex

81 vivo fluorescence microscopy. Fluorescent CSF tracers were slowly infused into the subarachnoid

82 CSF of the cisterna magna, and their results of tracer influx indicated the region-dependent

83 difference in the infiltration of fluorescent CSF tracers and higher amount of infiltration in the basal

84 brain regions of the 2-3-month-old C57BL/6 mice than 18-month-olds (Kress et al., 2014). These

85 results suggested the idea that CSF-infiltration into brain parenchyma is higher in the immature brain

86 and distinct brain regions are more permeable. However, the study has focused on the CSF/ISF

87 exchanges in aged disease brains and was not intended to find the CSF leakage through brain regions

88 thoroughly. Therefore, it remains unclear if such permeable regions are broader in younger brains

89 and along what vasculatures the CSF infiltration is distinct. In the present study, we aimed to reveal

90 regions with higher permeability of vasculature system in the earlier age of experimental animals

91 with a whole-brain visualization by dynamic contrast-enhanced magnetic resonance imaging (DCE-

92 MRI). We investigate whether Gd-signals are fairly constrained in the pathways of CSF at

93 developmental stages by injection from the cisterna magna. 


\section{Results}

\section{In vivo visualization of CSF flow using DCE-MRI from mouse brains.}

97 To investigate the in vivo CSF flow and CSF-permeation to the parenchyma in the course of

98 maturation in the entire vasculature system of the head, we visualized the flow dynamics and

99 infiltration of the Gd-signal in the brain parenchyma using 7T MRI system (Figure 1) (Materials \&

100 Methods). We used a Gd-based contrast agent GadoSpin M (Miltenyi Biotec, USA), with a low

101 molecular weight $(938 \mathrm{~g} / \mathrm{mol})$, which allows visualization of the leak of CSF (Aydin et al., 2008).

102 Upon injection into the cisterna magna (i.e., the posterior cerebellomedullary cistern), GadoSpin M

103 rapidly diffuses in the space of ventricles. To investigate the leakage of Gd-signal in the entire

104 vasculature system of the brain, we intentionally injected a high dose of Gd-contrast agent of 35-38

$105 \mu \mathrm{l}$ volume to fulfill the entire space of ventricles. Due to an opening called median aperture (foramen

106 of Magendie) between the cisterna magna and the fourth ventricle, our injection into the cisterna

107 magna made a substantial backflow to the fourth ventricle. The Gd-contrast agent reached the lateral

108 ventricles, which was seen in the previous experiment by Da Mesquita et al. (2018a) and Ahn et al.

109 (2019) (Figures 1B \& 1C). Gd-signals indicate the signals in infused ventricles, para-sinus,

110 lymphatic flow, and even parenchyma (Figures 1 \& 2). Additionally, from the lateral aperture

111 (foramen of Luschka) of the fourth ventricle Gd-contrast agent would have infused into the

112 subarachnoid space. Because of the very rapid transfer of the systemic circulation by pulsations, Gd-

113 contrast agent can circulate into the para-arteries and their signals were also visible within several ten

114 seconds. 
A
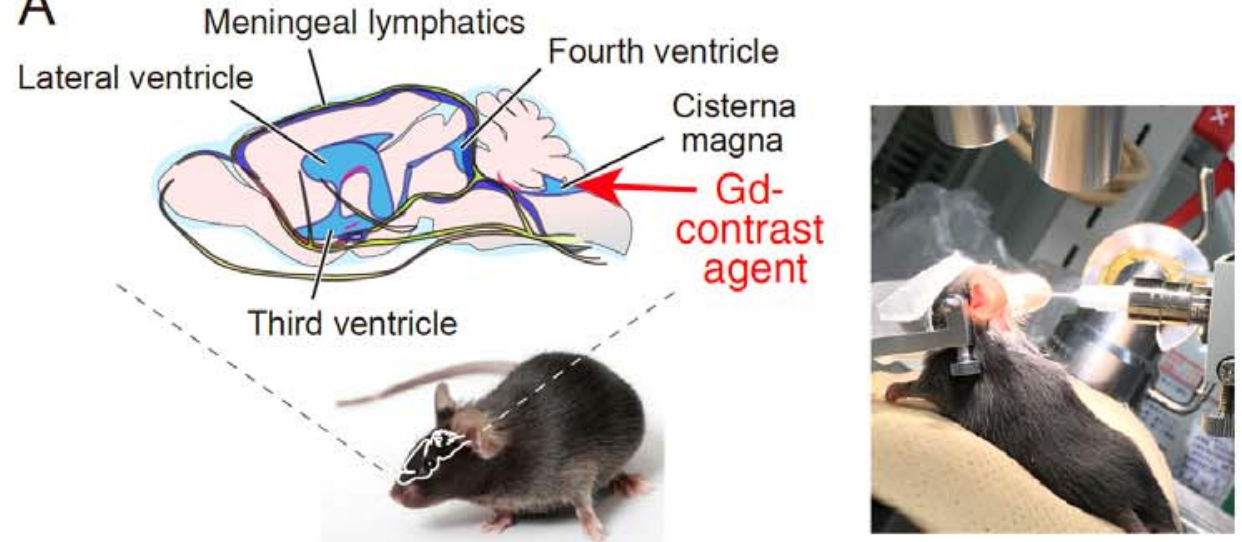

B
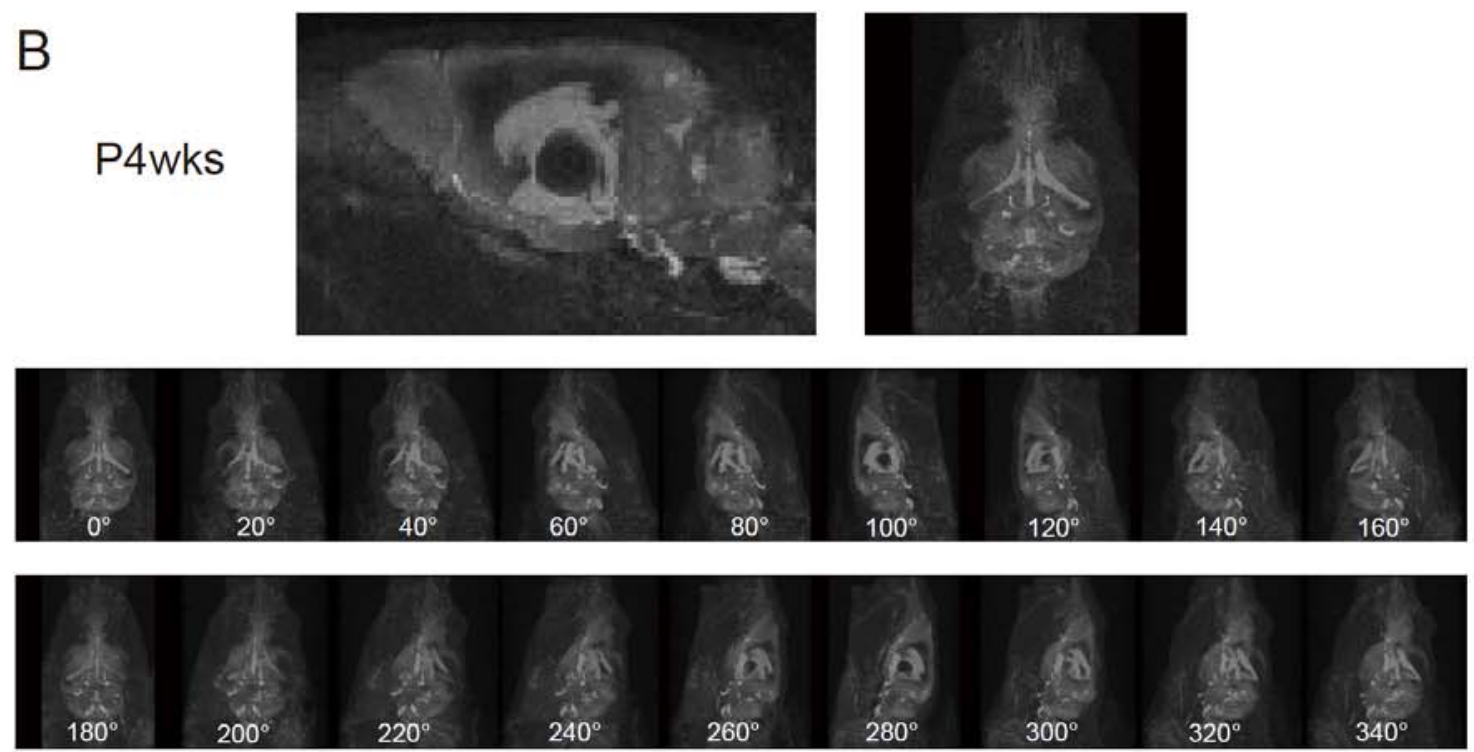

C

P4wks
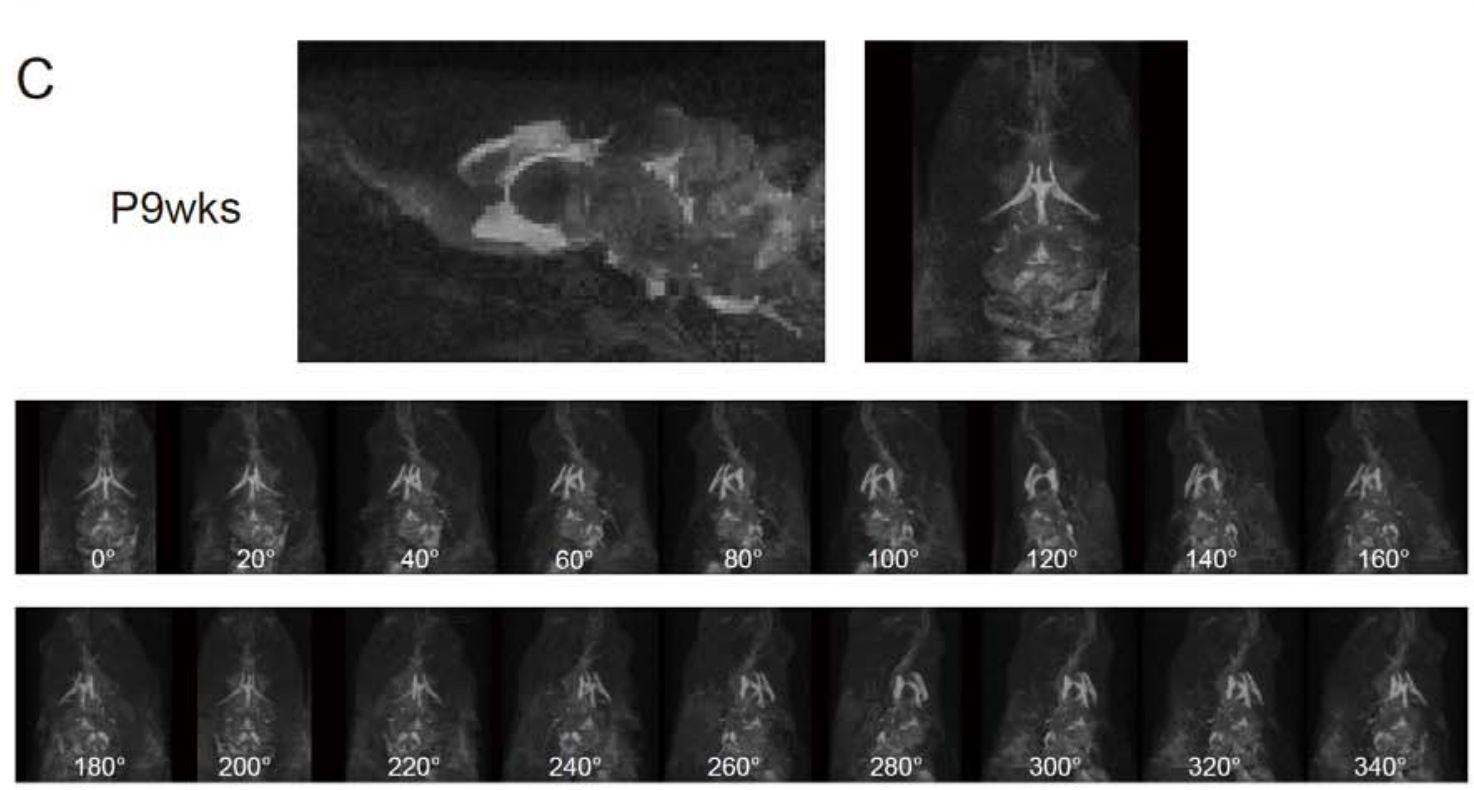


\section{Figure 1, Schematic illustration of vasculature system and 3D maximum intensity projection}

118 (MIP) images of whole head T1-weighted images of young (P4-weeks) and mature (P9-weeks)

\section{C57BL/6 mice.}

120 A, left, Brain lymphatic vessels (olive green), veins \& venous sinus (blue), and ventricles (sky blue) 121 are drawn. Right, Operation for the injection of Gd-contrast agent. A 27-gage needle is inserted into 122 the cisterna magna at a slow angle of negative 5 degrees from the front. After injection, we started 123 the MR imaging within 7-9 minutes. B, C, Sagittal, and horizontal views of T1-weighted MIP

124 images of the P4- and P9-week-old mice are shown (B and C, respectively). Each bottom low shows 125 the rotation of both representative brains at 20 degrees per frame. Please note the difference of Gd126 signals between P4- and P9-week-old mice. The images were captured at 9'00" (Frame 2). 
128 To compare the difference in the Gd-signals in the course of maturation, we investigated

129 signals at postnatal (P)4-weeks and P8-12 weeks (Figures 1B \& 1C). Right after the injection, we

130 started monitoring the Gd-signals for more than 2 hours. Gd-signals indicate a wider spread of the

131 contrast agent in the younger P4-week brain particularly from para-sinus and lymphatic flow

132 (Figures 1B \& 1C, Figure 2). In the mature P8-12-week brain, the CSF bulk flow with the Gd-

133 contrast agent injected into the cisterna magna is along the paths of the basal cistern to the olfactory

134 artery under isoflurane anesthesia, which represents the similar observation of Stanton et al. (2021).

135 According to Stanton et al. (2021), the Gd-contrast agent is distributed along the perivascular space

136 of the arteries in the subarachnoid space cisterns. From there, the contrast agent either infiltrates into

137 the parenchyma dorsally from the basal vasculature or continues as CSF bulk flow to efflux via the

138 nasal turbinates, and the pharyngeal lymphatic vessels. Distinct from the mature mouse, the CSF

139 flow is detected in the subarachnoid space cistern of the dorsal cerebrum in the P4-week brain

140 (Figures 1B \& 2A). 
B

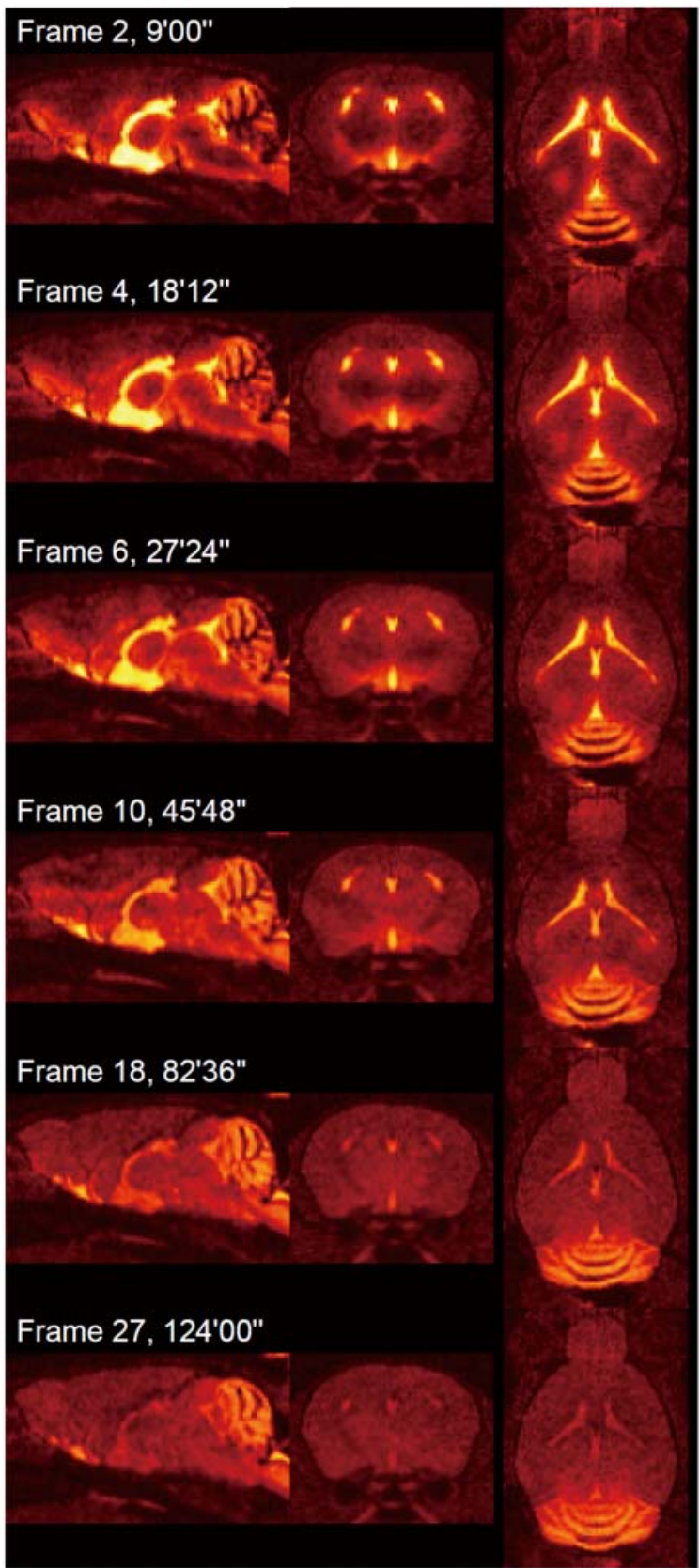

A

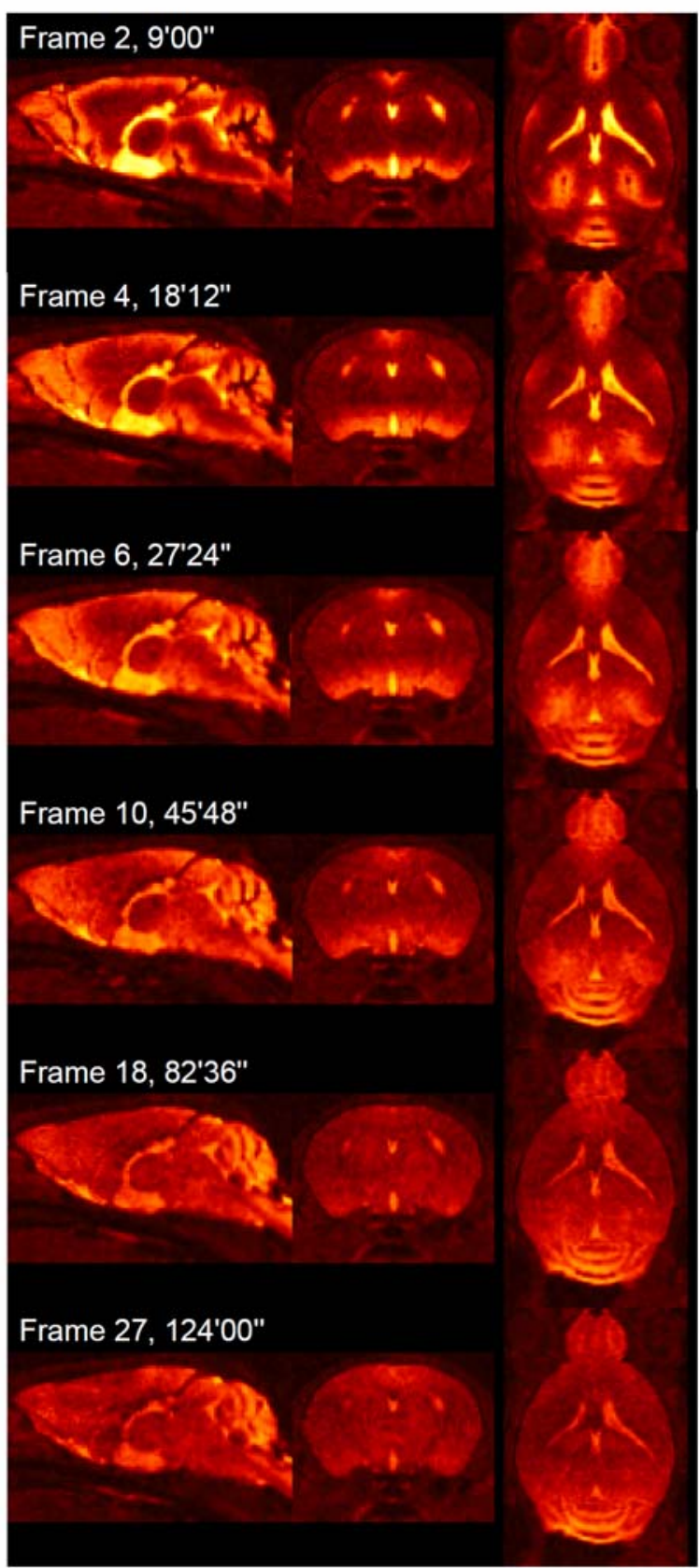

\section{P4wks}

143 P9-week-old mice.

Figure 2, Time-lapse images of Gd-signal-spread of whole head T1-weighted images of P4- and

A, Representative time-lapse images of Gd-signals of the P4-week-old animal are shown at the three 2D planes. B, Representative time-lapse images of Gd-signals of the P9-week-old animal are shown. As a baseline image, a non-contrast-enhanced image was taken before the injection of the Gdcontrast agent. The maximum duration for the start of the initial MRI acquisition as Frame 2 was 9 minutes throughout the study, and then, we use the time in the time display. 
As shown in the T1-weighted images (: sagittal, horizontal, and rotation images of the initial

152 flame), there are prominent differences between two developmental periods in the illuminated

153 regions in the brains: especially, the signals in the surface of the prefrontal cortex including anterior

154 cingulate cortex to the retrosplenial cortex along the rostral rhinal vein and the superior sagittal sinus

155 (SSS), midbrain along the aqueduct, and olfactory bulbs (Figures 1B \& 1C). At the parietal surface

156 regions of the neocortex, including areas along with the rostral rhinal vein and SSS, there are the

157 dorsal meningeal lymphatic vessels (Louveau et al., 2015). The previous studies suggested high

158 permeability of the fluorescent molecules to parenchyma in 2-month-old animals (Perry et al., 1997;

159 Kress et al., 2014), but these results suggest further permeability at younger one-month-old.

160 In Figure 2, the time-lapse images of the three 2D-planes (: Frame 2, 4, 6, 10, 18, and 27 at

161 9'00”, 18'12”, 27'24’, 45'48”, 82’36”, and 124'00”, respectively) show that CSF runs mainly into

162 the basal lymphatic outflow in both ages. To measure the time courses of the Gd-signals in the whole

163 brain regions, we first monitored the signals along the cisternae, ventricles, and sinuses (Figure 3).

164 We took 30 points of interest of those lymphatic vessels and ventricles (Extended Data Figure 3-1),

165 and we measured the Gd-signals along the pathway: cistern magna, aqueduct, the third ventricle,

166 lateral ventricle, olfactory artery, SSS, and other vasculatures. Obtained time courses of Gd-signals

167 in each region were normalized with the value of the maximum intensity of all the regions and mean

$168 \pm$ SEM are shown in Figure 3A as "Lymph \& Ventricles". 
A

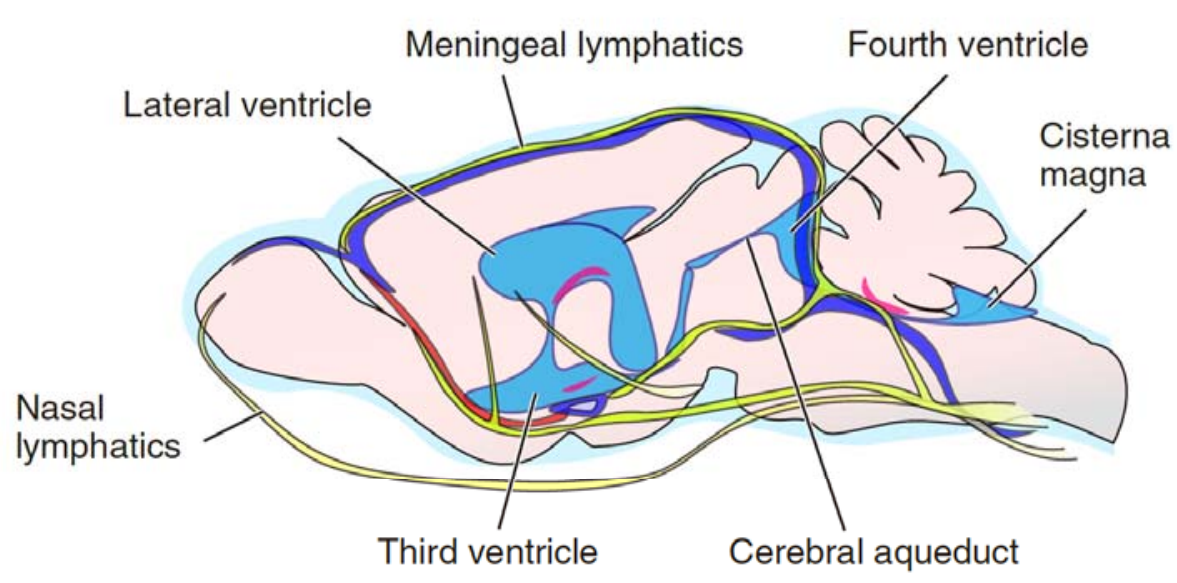

B

Lymph\&Ventricles
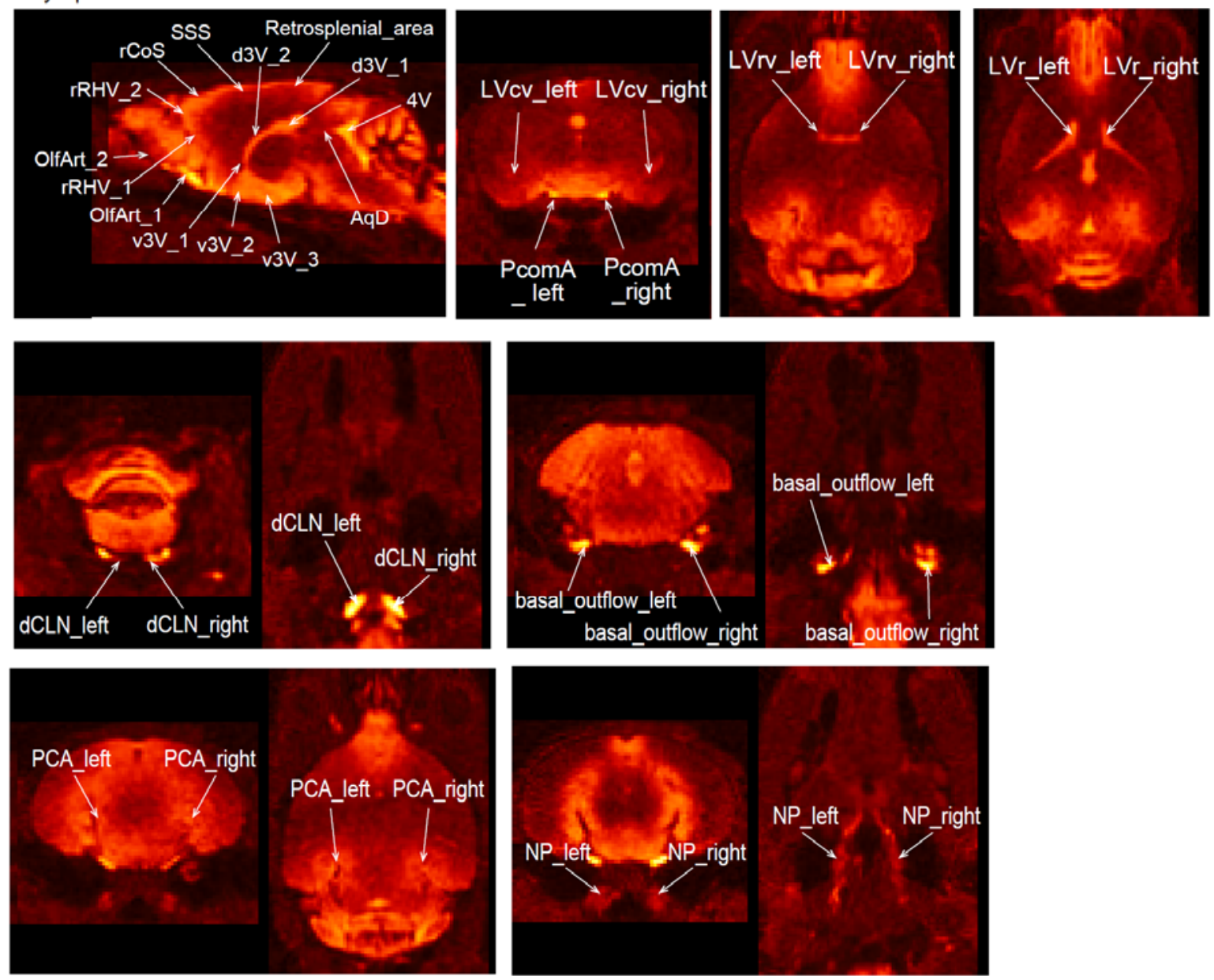

Extended Data Figure 3-1, Schematic illustration of vasculature system and illustrations of brain lymphatic vessels and ventricles with interest, Related to Figure 3.

$4 \mathrm{~V}$, fourth ventricle. $\mathrm{d} 3 \mathrm{~V}$, dorsal third ventricle. v3V, ventral third ventricle. AqD, aqueduct. dCLN,

174 deep cervical lymph node. $\mathrm{rCoS}$, rostral confluence of sinuses. LVcv, caudal ventral lateral ventricle.

175 LVrv, rostral ventral lateral ventricle. LVr, rostral lateral ventricle. NP, nasopharynx. OlfArt, 
bioRxiv preprint doi: https://doi.org/10.1101/2021.09.21.461189; this version posted September 24, 2021. The copyright holder for this preprint (which was not certified by peer review) is the author/funder. All rights reserved. No reuse allowed without permission.

176 olfactory artery. PCA, posterior cerebral artery. PcomA, posterior communicating artery. rRHV, 177 rostral rhinal vein. SSS, superior sagittal sinus.

178

179 


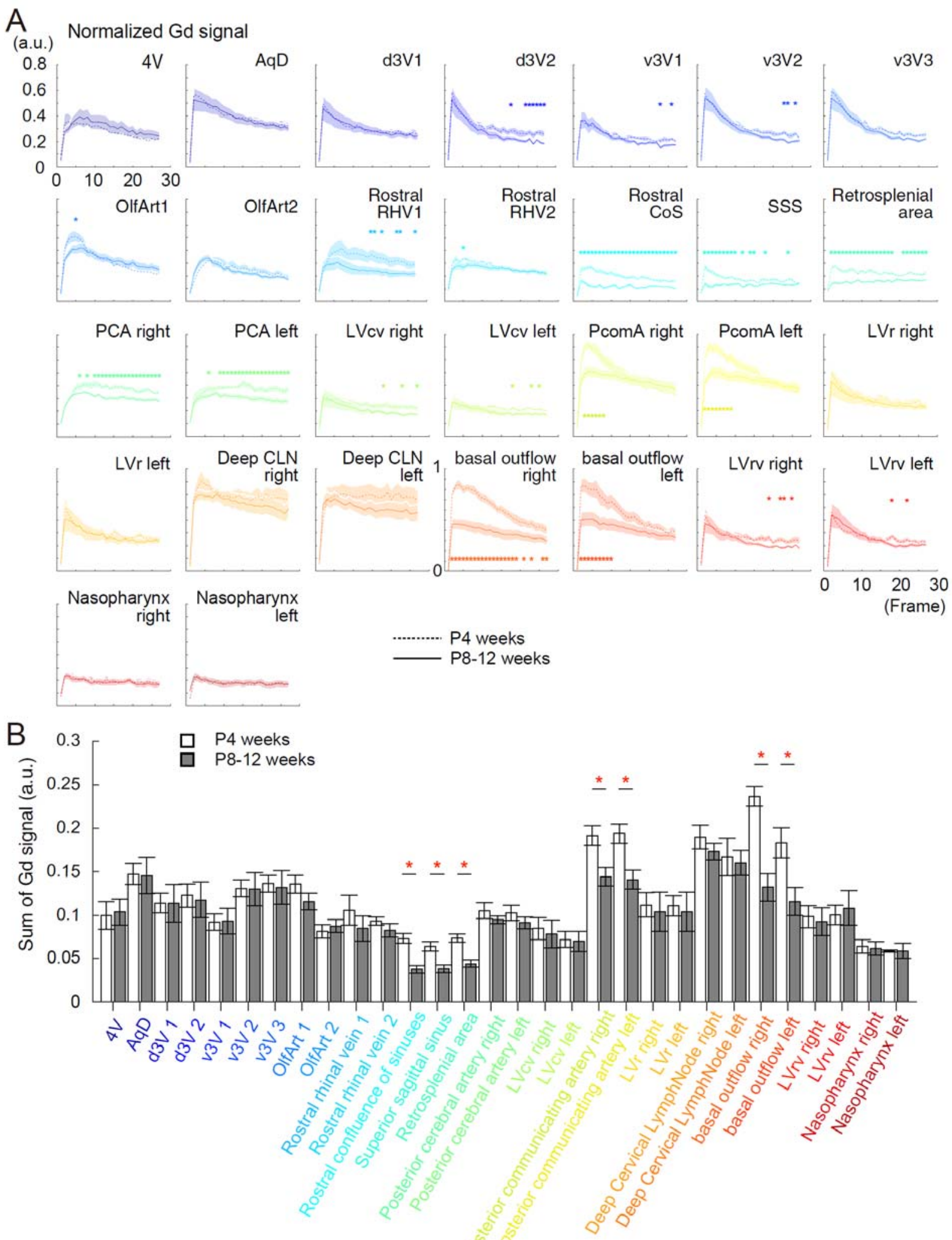


183 From the lymphatic vessels or ventricles ("Lymph \& Ventricles"), we took 30 points of interest

184 (Extended Data Figure 3-1). A, Time courses of the normalized Gd signals at different brain 185 regions of the lymphatic vessels and ventricles at two developmental stages (P4 and P8-12-weeks).

186 Frame 1 is taken before injecting the Gd-contrast agent. Frames 2-27 were taken with an interval of 4 $187 \mathrm{~min} 36 \mathrm{~s}$. The time courses of Gd-signals are shown as mean \pm SEM (mean: dotted line, P4-weeks; 188 solid line, P8-12-weeks, \pm SEM, delineated shadow). The time points with a significant difference 189 between the P4- and P8-12-weeks are asterisked (*p < 0.05). B, Summary bar graphs of accumulated 190 Gd-signals for $36 \mathrm{~min} 48 \mathrm{~s}$ (from Frame 2 to Frame 9) at two developmental stages of each region 191 (mean \pm SEM, blank and filled bars for P4- and P8-12-weeks, respectively). Significant differences 192 of "Lymph \& Ventricles" were found in the Rostral CoS (ranksum $=70, * p=0.001$ ), SSS (ranksum $193=75, * \mathrm{p}=0.0043)$, retrosplenial area $\left(\right.$ ranksum $\left.=71,{ }^{*} \mathrm{p}=0.0014\right)$, PcomA Right $\left(\right.$ ranksum $=78,{ }^{*} \mathrm{p}$ $194=0.0093)$, PcomA Left (ranksum $\left.=76,{ }^{*} \mathrm{p}=0.0056\right)$, basal outflow Right (ranksum $=69,{ }^{*} \mathrm{p}=$ 195 0.0008), and basal outflow Left (ranksum $=82, * \mathrm{p}=0.0282$ ). Otherwise, not significant.

$1964 \mathrm{~V}$, fourth ventricle. AqD, aqueduct. d3V, dorsal third ventricle. v3V, ventral third ventricle. OlfArt, 197 olfactory artery. Rostral RHV, rostral rhinal vein. Rostral CoS, rostral confluence of sinuses. SSS, 198 superior sagittal sinus. PCA, posterior cerebral artery. PcomA, posterior communicating artery. $199 \mathrm{LVcv}$, caudal ventral lateral ventricle. LVrv, rostral ventral lateral ventricle. LVr, rostral lateral 200 ventricle. dCLN, deep cervical lymph node. 
There is a wide range of variance in the normalized Gs-signals across the regions of

204 lymphatic vessels \& ventricles in each developmental stage. The normalized Gd-signals were high in

205 the basal brain regions and low in the dorsal brain regions. While the deep cervical lymphatic nodes

206 showed a rapid increase in the signals after Gd-injection, the signals remained high for a long

207 duration, representing the convergence of the brain drainage system of the lymphatic nodes. The

208 posterior communicating artery (PcomA) close to the pituitary recesses and the basal outflow also

209 showed high Gd-signals initially, but the time course of signals suggests a gradual attenuation of the

210 drainage (Figure 3A). We found the prominent difference between P4-week- and P8-12-week-old

211 mice in the signals of the basal outflows and PcomA, implying faster excretion of the brain CSF in

212 the young animals. In contrast, the other gland signals of the deep cervical lymphatic nodes and

213 nasopharynx did not show any significant differences between both developmental periods (Figure

214 3). In Figure 3B, the bar graphs of the cumulative normalized Gd-signals of the initial 8 Frames (:

215 from Frame 2 to Frame 9, for 36 min 48 s), again, indicate the distinct regions with high Gd-signals

216 in the young period. Along the regions of lymphatic vessels \& ventricles, there are the substantial

217 difference with significance between P4-week- and P8-12-week-old mice in the time points of Gd-

218 signals of the dorsal and ventral third ventricles, olfactory arteries, rostral rhinal veins, rostral

219 confluence of sinuses (CoS), SSS, retrosplenial area, posterior cerebral arteries, and caudal ventral

220 lateral ventricle. Notably, P4-week mice showed higher intensity in the signals of the rostral CoS,

221 SSS, and retrosplenial area than those of P-8-12 week mice (Figure 3B). Comparison of the time to

222 peak (Figure 5A; Extended Data Figures 5-1A\&B) and FWHM (Figure 5B; Extended Data

223 Figure 5-1A\&B) of Gd-signals also suggests the higher extent of Gd-signals in rostral rhinal vein,

224 rostral CoS, SSS, and retrosplenial area in P4-week group. These results suggest that the regions

225 along the basal artery to the rostral vein and retrosplenial areas have leaky ducts at P4-weeks,

226 whereas the leakage is shut down at P8- to P12-weeks. 
A
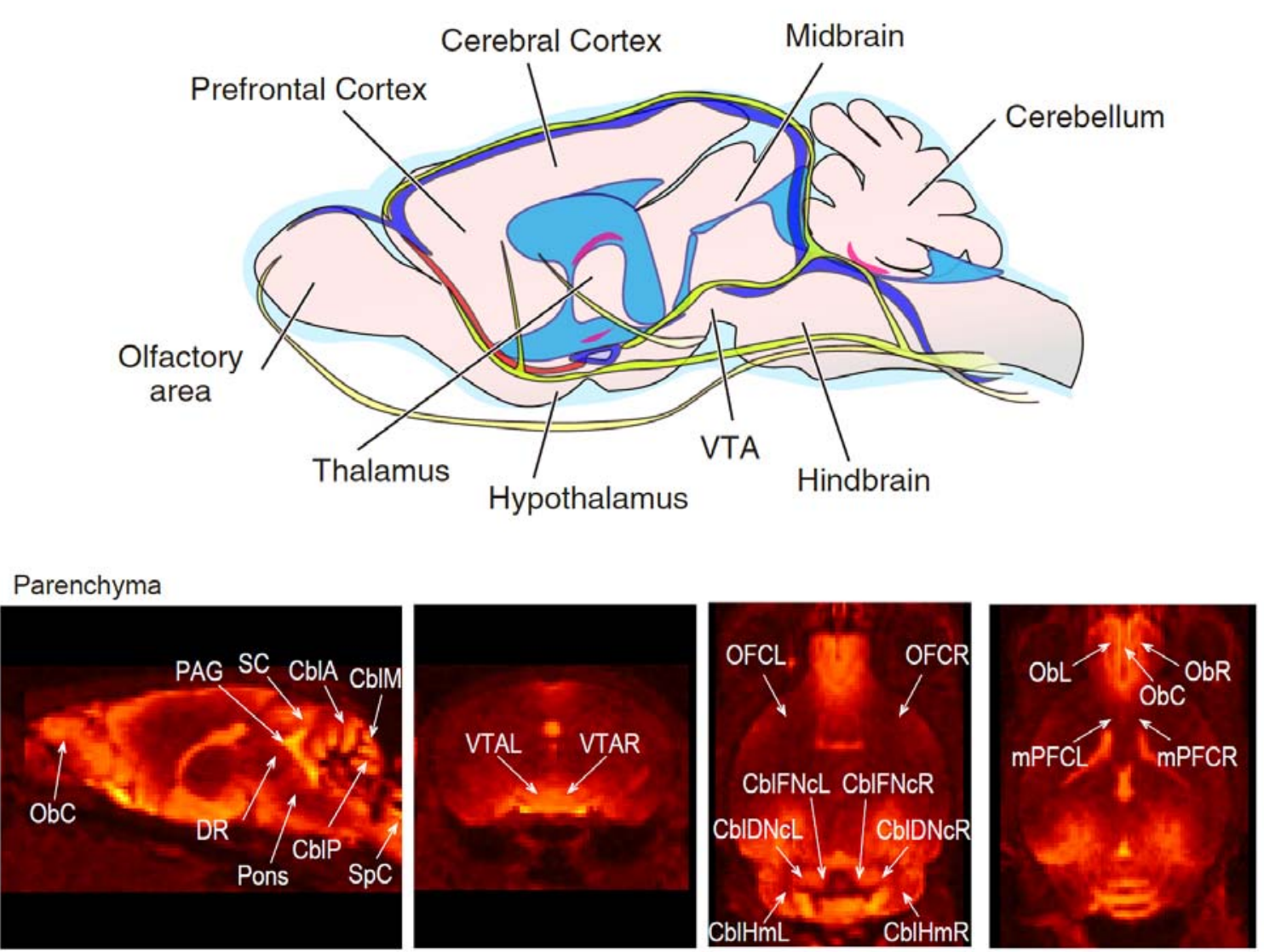

229 Extended Data Figure 4-1, Schematic illustration of brain parenchymal regions and 230 illustrations of brain parenchymas with interest, Related to Figure 4.

$231 \mathrm{CblA}$, anterior lobes of the cerebellar cortex. CblM, middle region (superior region of the posterior 232 lobes) of the cerebellar cortex. CblP, posterior lobes of the cerebellar cortex. CblHm, cerebellar 233 hemisphere. CblDN, dentate nucleus. CblFNc, fastigial nucleus. Dorsal Raphe, dorsal raphe nucleus. 234 mPFC, medial prefrontal cortex. Ob, olfactory bulb. OFC, orbitofrontal cortex. PAG, periaqueductal 235 gray. SC, superior colliculus. SpC, spinal cord. VTA, ventral tegmental area. R, C, and L indicate the 236 right, center, and left, respectively. 


\section{A Normalized Gd signal}
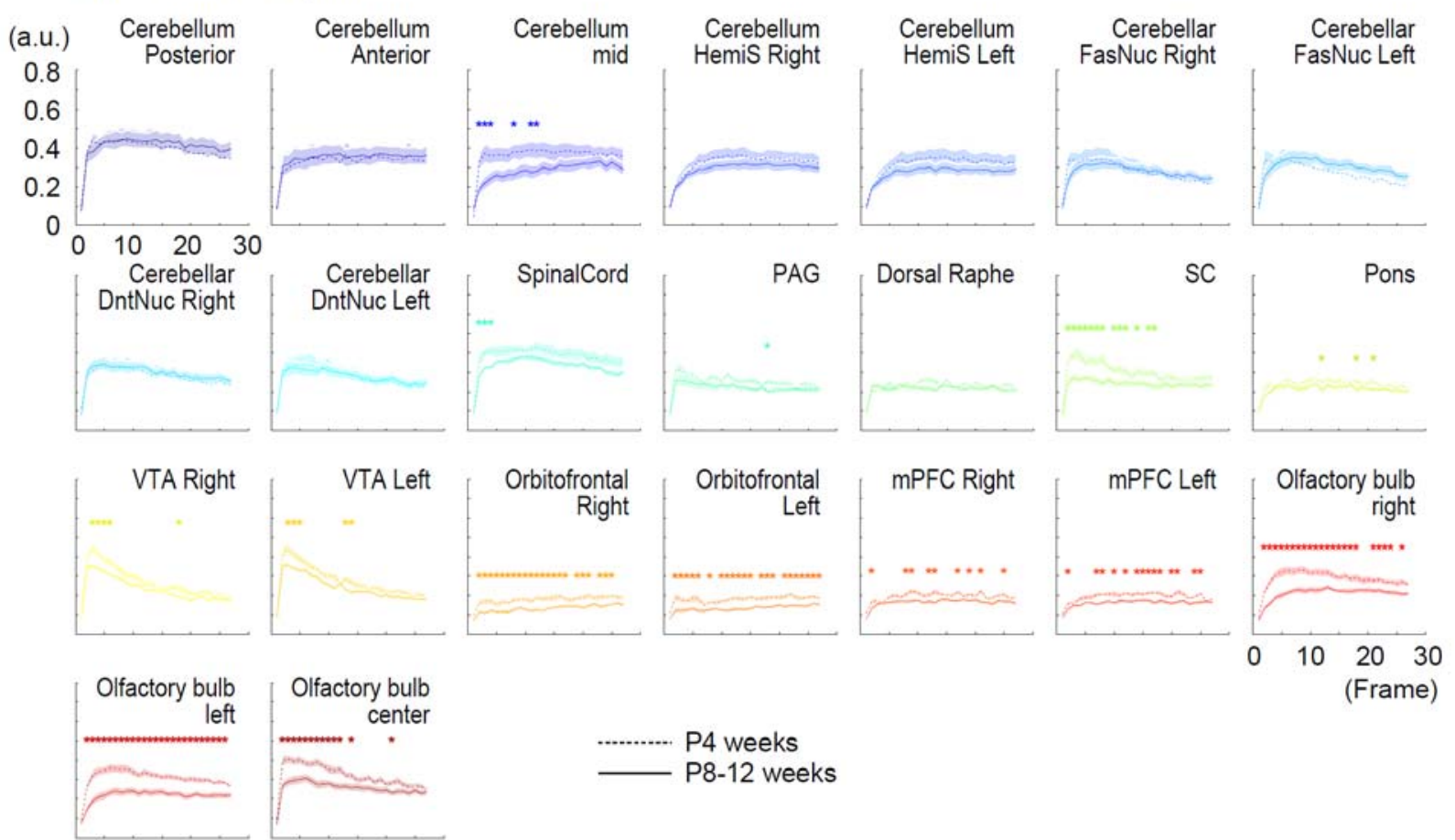

P4 weeks

P8-12 weeks

$$
\text { B }
$$

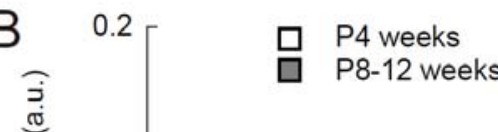

Figure 4, Increases in the Gd-signal of immature brains in the distinct regions of the brain parenchymas.

From the brain parenchymas ("Parenchyma"), we took 23 points of interest (Extended Data Figure developmental stages (P4 and P8-12-weeks). Frame 1 is taken before injecting the Gd-contrast agent. Frames 2-27 were taken with an interval of $4 \min 36 \mathrm{~s}$. The time courses of Gd-signals are shown as mean \pm SEM (mean: dotted line, P4-weeks; solid line, P8-12-weeks, \pm SEM, delineated shadow). 
246 The time points with a significant difference between the P4- and P8-12-weeks are asterisked $(* \mathrm{p}<$ 247 0.05). B, Summary bar graphs of accumulated Gd-signals for 36.8 minutes (from Frame 2 to Frame 248 9) at two developmental stages of each region (mean \pm SEM, blank and filled bars for P4- and P8-

249 12-weeks, respectively). Significant differences of "Parenchyma" were found in the Cerebellum mid 250 (ranksum $=84, * \mathrm{p}=0.035)$, Spinal Cord (ranksum $=85, * \mathrm{p}=0.0426), \mathrm{SC}($ ranksum $=80, * \mathrm{p}=$ $2510.0149)$, VTA Right (ranksum $=83, * p=0.0286)$, VTA Left (ranksum $=85, * p=0.0426)$, 252 Orbitofrontal Right (ranksum $\left.=77,{ }^{*} \mathrm{p}=0.0072\right)$, Orbitofrontal Left (ranksum $=80,{ }^{*} \mathrm{p}=0.0149$ ), 253 mPFC Left (ranksum $=85, * p=0.0426)$, Olfactory bulb Right (ranksum $=72, * p=0.0019)$, 254 Olfactory bulb Left (ranksum $=73, * \mathrm{p}=0.0025)$, and Olfactory bulb center (ranksum $=72, * \mathrm{p}=$ 255 0.0019). Otherwise, not significant.

256 Cerebellum Posterior, posterior lobes of the cerebellar cortex. Cerebellum Anterior, anterior lobes of 257 the cerebellar cortex. Cerebellum mid, middle region (superior region of the posterior lobes) of the 258 cerebellar cortex. Cerebellum HemiS, cerebellar hemisphere. CerebellarFasNuc, fastigial nucleus. 259 CerebellarDntNuc, dentate nucleus. SpinalCord, spinal cord. PAG, periaqueductal gray. Dorsal 260 Raphe, dorsal raphe nucleus. SC, superior colliculus. VTA, ventral tegmental area. Orbitofrontal, 261 orbitofrontal cortex. mPFC, medial prefrontal cortex. 

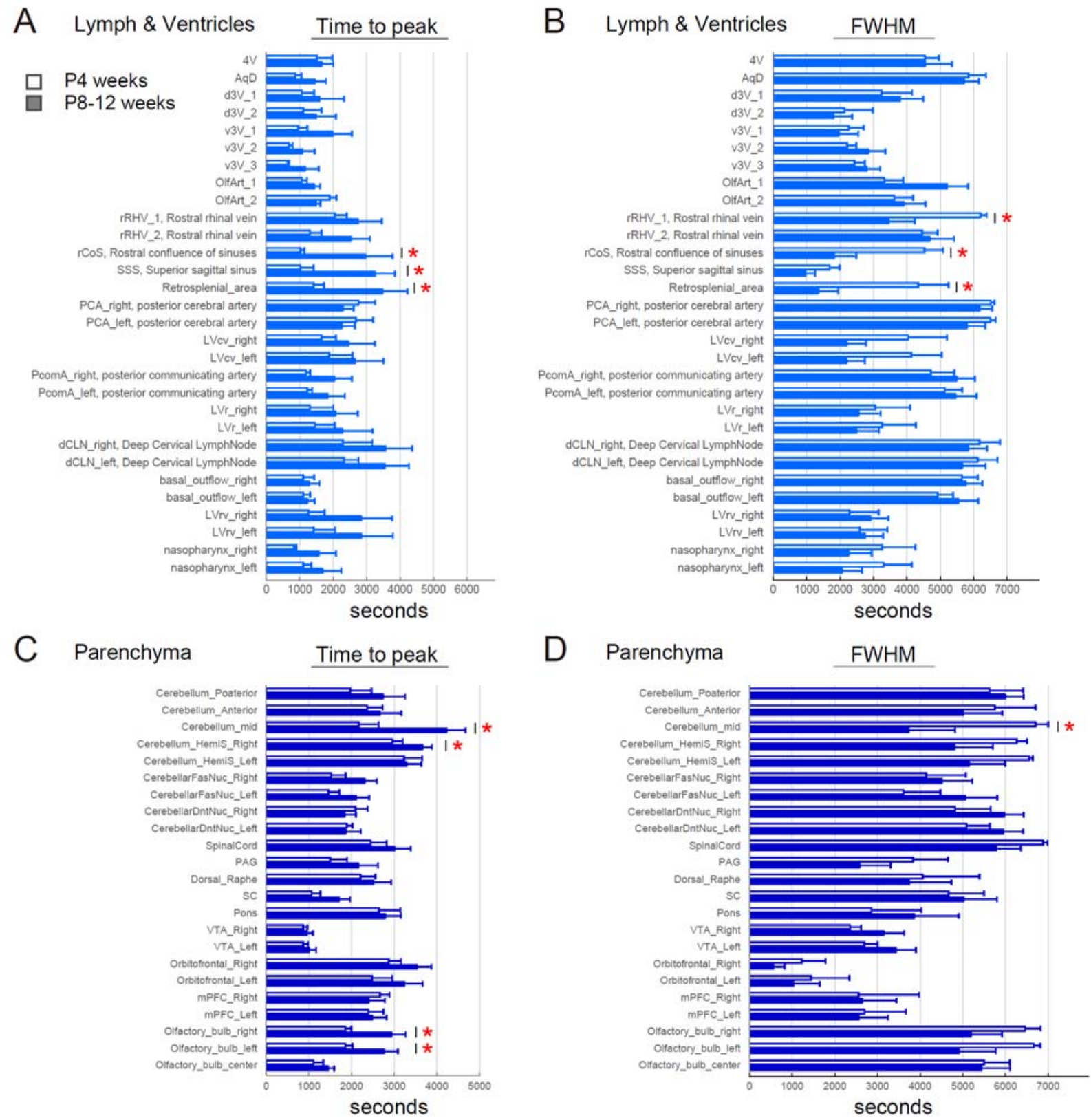

Figure 5, Time to peak and full width at half maximum (FWHM) of all the normalized Gd 265 signals at different brain regions of the lymphatic vessels and ventricles, and parenchymas at 266 two developmental stages.

267 All the times to peak and FWHMs are shown in each group by developmental stages (P4- vs P8-12268 weeks) and by vasculature - parenchyma axis for the comparison of the waveforms in each brain 269 region. Bar graphs and error bars show mean \pm SEM of time to peak (A and C) and FWHM (B and 270 D) (Blank bar: P4-weeks. Filled bar: P8-12-weeks.). Asterisks indicate significant differences at the 271 level of $\mathrm{p}<0.05$ by two-tailed Student's $t$-test with unequal variances because two sampled groups 272 are from the same distribution. In A of the time to peak, significant differences of "Lymph \& 273 Ventricles" were found in the $\operatorname{rCoS}(\mathrm{t}(10.4)=2.331, * \mathrm{p}=0.0411), \operatorname{SSS}(\mathrm{t}(12.7)=3.089, * \mathrm{p}=$ $2740.0088)$, and retrosplenial area $(\mathrm{t}(11.8)=2.564, * \mathrm{p}=0.0252)$. Otherwise, not significant. In B of the 275 FWHM, significant differences of "Lymph \& Ventricles" were found in the rRHV_1 (t $(11.1)=$ - 
$2763.393, * \mathrm{p}=0.0059), \mathrm{rCoS}(\mathrm{t}(14.0)=-3.085, * \mathrm{p}=0.0081)$, and retrosplenial area $\left(\mathrm{t}(11.0)=-2.746,{ }^{*} \mathrm{p}\right.$ $277=0.0190)$. Otherwise, not significant. In $\mathrm{C}$ of the time to peak, significant differences of

278 "Parenchyma" were found in the Cerebellum_mid $\left(\mathrm{t}(14.1)=3.180,{ }^{*} \mathrm{p}=0.0066\right)$,

279 Cerebellum_HemiS_Right $\left(\mathrm{t}(14.3)=2.173,{ }^{*} \mathrm{p}=0.0470\right)$, Olfactory_bulb_right $\left(\mathrm{t}(13.3)=2.996,{ }^{*} \mathrm{p}\right.$ $280=0.0101)$, and Olfactory_bulb_leftt $(\mathrm{t}(14.4)=2.497, * \mathrm{p}=0.0252)$. Otherwise, not significant. In D 281 of the FWHM, significant differences of "Parenchyma" were found in the Cerebellum_mid $(\mathrm{t}(8.0)=$ $282-2.652, * \mathrm{p}=0.0291)$. Otherwise, not significant. 

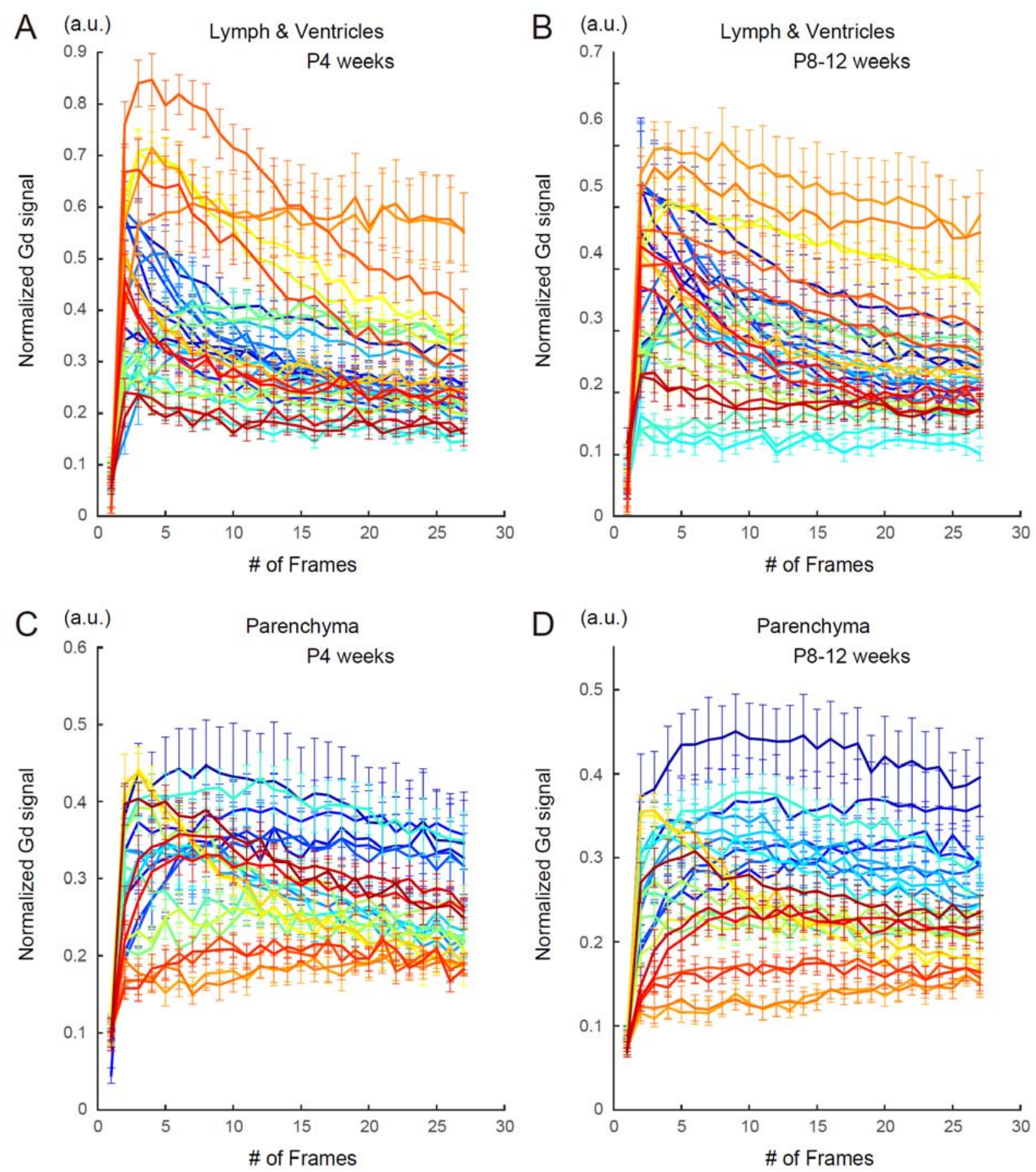

Extended Data Figure 5-1, Time-courses of all the normalized Gd signals at different brain regions of the lymphatic vessels and ventricles and parenchymas at two developmental stages 288 (P4 and P8-12-weeks), Related to Figure 5.

All the time courses shown in Figures 3A and 4A are classified and displayed in each group by each brain region. The color code is matched to that in Figures $3 \& 4$. 
Next, to examine the time courses of the Gd-signals in the brain parenchyma, we took 23

294 points of interest (Figure 4; Extended Data Figure 4-1) and measured the normalized Gd-signals of

295 the cerebellar cortex, cerebellar nuclei, spinal cord, periaqueductal gray, dorsal raphe, superior

296 colliculus (SC), Pons, ventral tegmental area (VTA), orbitofrontal cortex, medial prefrontal cortex

297 (mPFC), and olfactory bulb (as "Parenchyma"). There is also a wide range of variance in the

298 normalized signal intensity of the regions of Parenchyma. The normalized Gd-signals were also high

299 in the basal brain regions, such as VTA. On the other hand, the normalized Gd-signals were also high

300 intensity in the posterior brain regions and low in the frontal cortex, reflecting that the Gd-signals in

301 the parenchyma were polarized in the rostral-caudal axis in the cisterna magna injections (Kress et al.,

302 2014). The normalized Gd-signals were significantly higher in P4-week-old animals than that in P8-

303 12-week-old animals in the regions of SC, VTA, orbitofrontal cortex, and olfactory bulbs. In the

304 middle lobules of the cerebellar cortex (the superior region of the posterior lobes), spinal cord, pons,

305 and mPFC showed transient but significantly higher Gd-signals in the young animals (Figure 4A).

306 The time courses of Gd-signals appeared faster in the brain vasculatures (in lymphatic vessels \&

307 ventricles, Figure 3A) than those of the brain parenchymal area expected for the VTAs (Figure 4A;

308 Figure 5), suggesting slow infiltration of the CSF into the parenchyma. Compared to the other

309 regions of parenchyma, the time courses of the cerebellar cortex and nuclei showed longer rise time

310 to the peak and longer decay (Cerebellum mid, Cerebellum HemiS, CerebellarFasNuc, and

311 CerebellarDntNuc in Figure 4A and Figure 5C\&D). In the BBB, AQP-4 expressing at the endfeet

312 of astrocytes dominantly filters the CSF at most of the brain parenchymal regions (Nielsen et al.,

313 1997). A chicken study suggest a fewer level of AQP-4 expression in the cerebellar molecular layer

314 but a high expression pattern along the entire pial surface, Bergmann glial fiber terminals, and

315 perivascular processes facing the capillaries, which may occur in the mouse brain and may delay the

316 infiltration (Nico et al., 2002). In Figure 4B and Figure 6, the bar graphs of the cumulative

317 normalized Gd-signals of the initial and late period (from Frame 17 to Frame 27) again indicate the 
318 distinct regions with high Gd-signals in the young period: in the cerebellar cortex, spinal cord, SC,

319 VTA, orbitofrontal cortex, mPFC, and olfactory bulb. Time to peak and FWHM of Gd-signals also

320 support the parenchymal regions with high Gd-permeability (Figure 5; Extended Data Figure 5-1).

321 As far as we know, no developmental differences in the cerebrovascular function and the vascular

322 running have been reported during this experimental period. These results of the DCE-MRI imply

323 that the immature barrier function of the vasculature system including the lymphatic vessels and the

324 BBB allows the infiltration of low molecular weight substances and, perhaps, cells to infiltrate

325 parenchyma in those areas.

326 Lastly, we confirmed no microhemorrhages in immature brains in vivo by visualizing the

327 artery distribution in P4-week mouse brains using MRA. Since MRA contrasts the fast blood fluid

328 flow, it mainly indicates the arterial blood flow. Our observation did not find any leakage of the

329 blood vessels (Figure 7), suggesting that the artery is intact and other perivascular space such as

330 capillary, the subarachnoid space, and meningeal lymphatic vessels would be the sites of leakage. 

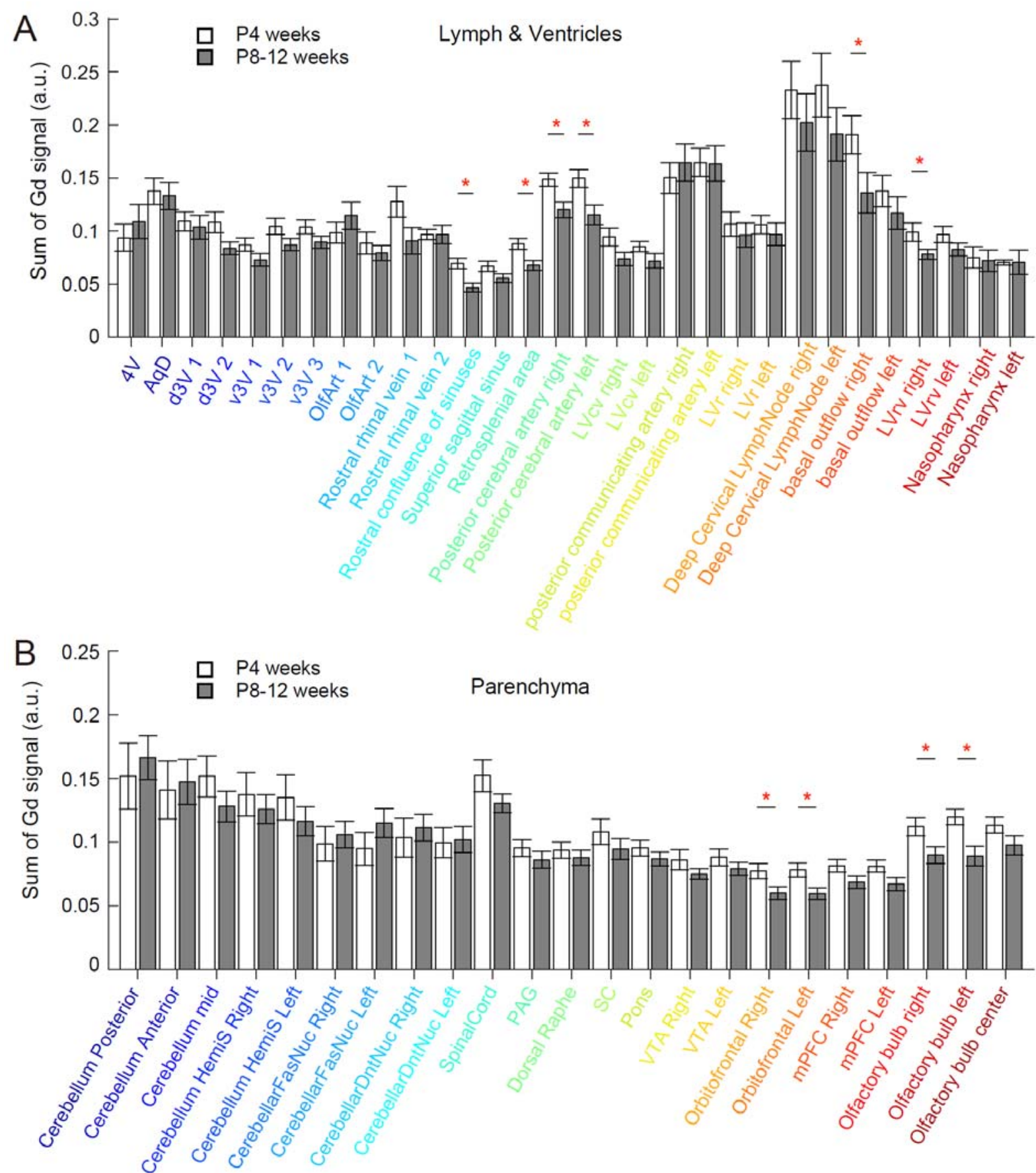

Figure 6, Summary bar graphs of accumulated Gd-signals in the late phase of experiments.

A, Summary bar graphs of accumulated Gd-signals in the late phase of experiments for 50.6 minutes (from Frame 17 to Frame 27; i.e., from 77'00" to 124'00') at two developmental stages of the lymphatic vessels and ventricles (mean \pm SEM, blank and filled bars for P4- and P8-12-weeks, respectively). Significant differences of "Lymph \& Ventricles" were found in the Rostral CoS (ranksum $\left.=75,{ }^{*} p=0.0043\right)$, retrosplenial area (ranksum $\left.=80,{ }^{*} p=0.0149\right)$, PcomA Right $($ ranksum $=80, * p=0.0149)$, PcomA Left (ranksum $=81, * p=0.0186)$, LVrv right (ranksum $=84$, $* \mathrm{p}=0.035)$, basal outflow Right (ranksum $=85, * \mathrm{p}=0.0426)$, and LVrv right $\left(\right.$ ranksum $=83,{ }^{*} \mathrm{p}=$ 0.0286). Otherwise, not significant. 
bioRxiv preprint doi: https://doi.org/10.1101/2021.09.21.461189; this version posted September 24, 2021. The copyright holder for this preprint (which was not certified by peer review) is the author/funder. All rights reserved. No reuse allowed without permission.

342 B, Summary bar graphs of accumulated Gd-signals in the late phase of experiments of the 343 parenchymas. Significant differences of "Parenchyma" were found in the Orbitofrontal Right 344 (ranksum $\left.=83,{ }^{*} \mathrm{p}=0.0286\right)$, Orbitofrontal Left (ranksum $\left.=79,{ }^{*} \mathrm{p}=0.0118\right)$, Olfactory bulb Right 345 (ranksum $=80,{ }^{*} \mathrm{p}=0.0149$ ), and Olfactory bulb Left (ranksum $=78,{ }^{*} \mathrm{p}=0.0093$ ). Otherwise, not 346 significant.

347 


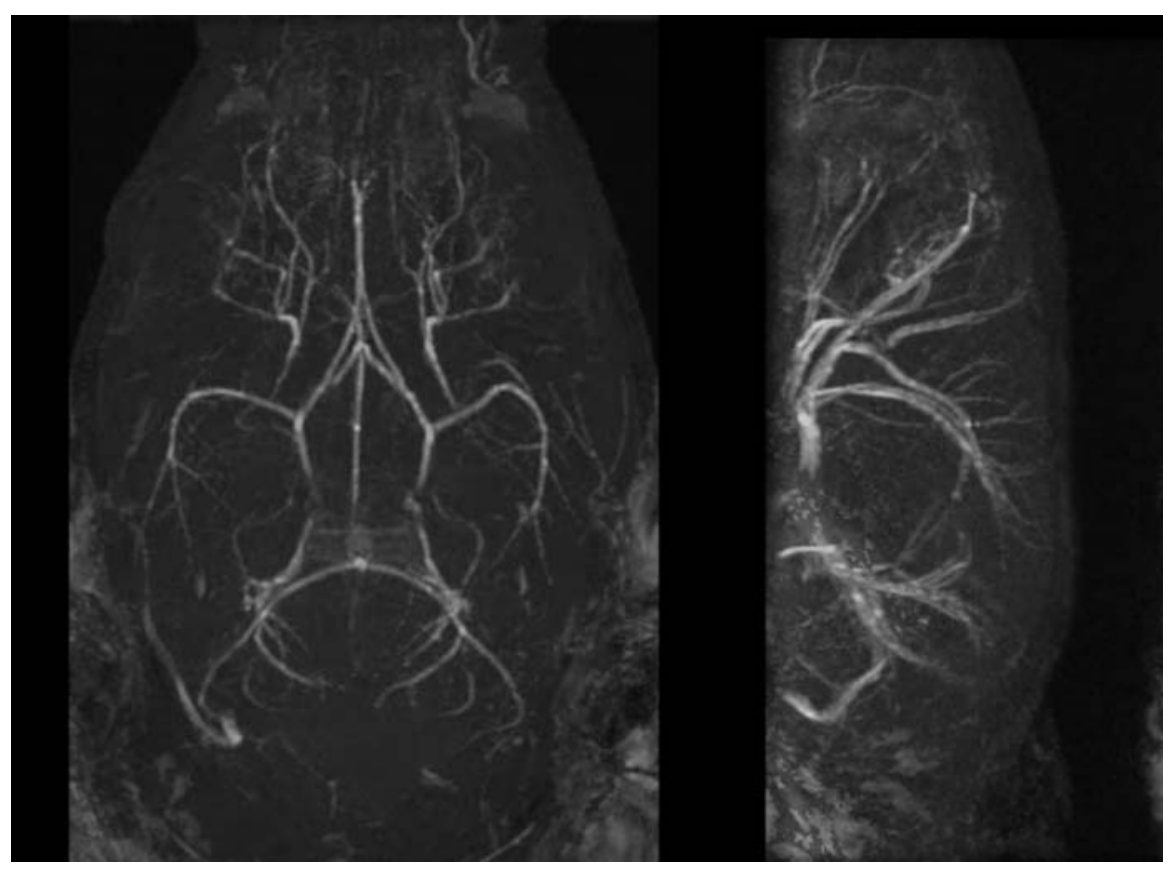

\section{Figure 7, MR angiograms of a young (P4-weeks) C57BL/6 mouse.}

350 Horizontal (left) and sagittal (right) views of representative MRA projection images are displayed.

351 No detectable microhemorrhages were observed in the brain arteries. Isotropic spatial resolution of $352100 \mu \mathrm{m}$. 


\section{Discussion}

355 In this study, we monitored the bulk CSF flow using DCE-MRI and compared the Gd-signals along

356 with the brain lymphatic flow and in the brain parenchymal regions. According to Stanton et al.

357 (2021), the Gd-contrast agent injected into the cisterna magna is distributed along with the

358 perivascular space of the blood vessels in the subarachnoid space cisterns, and the contrast agent

359 infiltrates into the parenchyma. In P4-week animals, the Gd-signals showed higher intensity in

360 distinct regions of brain parenchyma, such as the olfactory bulb, prefrontal cortex, parietal surface

361 regions of the neocortex along with SSS, ventral midbrain, and a part of cerebellum, as well as in the

362 basal brain regions, compared to mature P8- to P12-week-old mice (Figures 3-6). No substantial

363 leakage of the arterial flow by MRA (Figure 7) implied that the infiltration of Gd-signals comes

364 from the subarachnoid space, perivascular space along blood vessels and capillaries, and meningeal

365 lymphatic vessels. Our results suggest that the CSF barrier in mouse brains is still permeable until P4

366 weeks.

A distinct leak in Gd-signals even at the timing when the BBB integrity is established.

Previous studies by Bauer et al. (1995) using the injection of Trypan blue via the umbilical

370 vein suggested that the staining substance does not infiltrate into the CSF space from the systemic

371 circulation, and such a barrier is established in the early embryonic stage. Although injected Trypan

372 blue had been excluded from most parts of the central nervous system (CNS), those experiments did

373 not necessarily indicate the impermeability of CSF into the brain parenchyma nor the functional

374 completion of BBB. On the other hand, electrical resistance across BBB in anesthetized rodents was

375 also measured previously (Butt et al., 1990), and the averaged transendothelial electrical resistance

376 (TEER) at one-month-old was higher up to five times than that immediately before the birth. The

377 result had been regarded to demonstrate the rapid maturation of BBB. However, it did neither

378 necessarily indicate the completion of all the BBB-barriers because measured resistance showed a 
379 great variance among the samples $\left(30-5900 \Omega \mathrm{cm}^{2}\right)$. Most of the TEER of one-month-old rats was

380 less than $1000 \Omega \mathrm{cm}^{2}$, and the TEER of veins $\left(800 \Omega \mathrm{cm}^{2}\right)$ was significantly lower than that of the

381 artery (Butt et al., 1990). The barrier should become functional during postnatal maturation, but it

382 had been unclear at which developmental stage the BBB-barrier is fully established (Bauer HC et al.,

383 2014). In this study, DCE-MRI allowed us to visualize how the small molecule spreads and

384 infiltrates into the CSF space in the entire brain region. And we found distinct Gd-signals in

385 parenchymas at $\mathrm{P} 4$ weeks, which is the later stage than the timing when normally believed the BBB

386 is completed. However, a low resolution of the MRI method limits our interpretation of how the Gd-

387 contrast agent permeates into the parenchyma and with what machinery works for the developmental

388 changes.

389 A possibility of the permeability along the immature meningeal lymphatic vessels

390 Due to the functional identities, there are two canonical vasculature systems in the brain: the

391 meningeal lymphatic vessels and the glymphatic system (Louveau et al., 2017). Given a certain leak

392 across to the parenchymal regions as the underlying mechanism, we may raise the following

393 assumptions to account for our observations of the difference between P4-week and P8-12-week

394 mouse brains. One possibility is that the meningeal lymphatic vessels are still permeable at postnatal

395 development. In CSF production at the blood-CSF barrier, the choroid plexus absorbs water via

396 aquaporin (AQP)-1 and ions from the blood, generating CSF in the ventricles and subarachnoid

397 spaces (Dietz et al., 2020; Segawa et al., 2021). CSF circulates via thin lymphatic ducts in the

398 meninges (: meningeal lymphatic vessels). The flow stream of CSF and meningeal lymph is thought

399 substantially driven by the pulsatile and cerebral perfusion pressure. CSF in the subarachnoid space

400 flows into the venous sinus via arachnoid granulations (Rustenhoven et al., 2021; Ringstad \& Eide,

401 2020). The recent rediscovery of the meningeal lymph elucidated that the lymphatic network

402 scavenges macromolecules and waste products of tissues and secures immune cells into the CNS

403 (Louveau et al., 2015, 2018; Aspelund et al., 2015; Absinta et al., 2017; Da Mesquita et al., 2018b). 
404 The leaky barrier function of meningeal lymphatic vessels and the reduction of brain perfusion of

405 CSF macromolecules in aged brains are suggested as a hallmark of the cognitive impairment (Da

406 Mesquita et al., 2018a; Sweeney et al., 2018; Ahn et al., 2019). Lymphatic endothelial cells (LECs)

407 form both button-like junctions (high permeability for the initial lymphatic vessels) and zipper-like (:

408 tight barrier) junctions, both of which are composed of adherens and tight junctions. In mature P3-

409 month-old mice, more than $60 \%$ of junctions between LECs of dorsal meningeal lymphatic vessels

410 are zipper-like, and around $20 \%$ are button-like (Ahn et al., 2019), suggesting the leakage would be

411 shut-down as seen in P2- to P3-month-old mice of our results. Such a button-like structure in the

412 dorsal forebrain may allow infiltration of the Gd-contrast agent. Therefore, the meningeal lymph and

413 associated veins in the juvenile brains may be leaky because of the dominance of button-like

414 junctions or their immaturity.

\section{A possibility of functionally immature BBB}

416 The glymphatic system is another brain perfusion machinery for CSF (Iliff et al., 2012, 2013).

417 The Gd-contrast agent flows along with the perivascular space of the blood vessels in the

418 subarachnoid space cisterns and possibly infiltrates into parenchyma via the BBB. Thus, the second

419 possibility is that the leaky CSF barrier between the perivascular space and parenchyma.

420 Vasculatures and capillaries are coated by the astrocytic endfeet, and the AQP-4 existing there is the

421 major gateway for the CSF/ISF exchange of the BBB. AQP-4 expresses in the embryonic mouse

422 brain at E16, and a polarized localization for organizing the water gateway emerges at P1- to P3-days

423 (Fallier-Becker et al., 2014). A study by Kress et al. (2014) suggested the attenuated CSF tracer

424 influx into the parenchyma in the course of development from 2- to 3-month- to 18-month-old mice

425 due to loss of perivascular AQP-4 polarization in the aged brains. Contrary to this, our results

426 indicate higher permeability in one-month-old mice in distinct brain regions.

427 The BBB is tightly regulated by the expansion of the microvascular network and the volume

428 expansion of the brain during maturation (Coelho-Santos \& Shih, 2020). Over weeks after birth, the 
429 cortical microvasculature network undergoes dramatic expansion via capillary angiogenesis (Risau \&

430 Wolburg, 1990; Risau, 1997; Marín-Padilla, 2012; Harb et al., 2013). Volumetric measurements

431 suggested that the mouse brain keeps expanding at least until the end of postnatal one month, and the

432 rate is high in the neocortex and the cerebellum (Zhang et al., 2005). Thus, maturation of the

433 cerebrovascular capillaries lasts during the postnatal period (Coelho-Santos \& Shih, 2020).

434 Considering the infiltration of the CSF from the perivascular space to the parenchymas, the

435 functionality of the BBB could be incomplete during that period. Our findings of the high intensity

436 of Gd-signals in the juvenile brain in the olfactory bulbs, mPFC, orbitofrontal cortex, the upper part

437 of the cingulate cortex nearby the longitudinal fissure (i.e., rostral CoS, SSS, and retrosplenial area),

438 SC, VTA, peripheral regions of the posterior cerebral artery (: the border regions between the

439 midbrain and posterior hippocampus), and middle lobules of the cerebellum suggest the leaky barrier

440 in those regions (Figure 4). Although our MRA observation did not support any microvasculature

441 leakage in the arteries (Figure 7), the CSF infiltration may occur in the microstructure at a slow

442 speed.

443 Strand breaks of tight junctions (TJs) are known to occur during maturation and

444 inflammatory states of diseases (Huber et al., 2001; Varadarajan et al., 2019; Greene et al., 2019).

445 TJs between cerebrovascular endothelial cells as blood endothelial cells (BECs) form a strong barrier

446 (Butt et al., 1990). Besides, the interaction of astrocyte endfeet and pericytes to BECs leads to the

447 formation of BBB with a fenestrated barrier. The junctions between BECs include TJs, adherens

448 junctions, and gap junctions. The TJs are composed of claudins, occludin, and ZO-1 accompanied

449 with JAMs. In BBB, a barrier-forming type claudin-5 is the major component (Nitta et al., 2003),

450 while other claudins are also known to compose the BEC TJs (Berndt et al., 2019). In claudin-5

451 knockout and knockdown mice, the cerebrovascular permeability is significantly increased, and the

452 BBB was revealed to permeate substances with at least up to $800 \mathrm{Da}$ of the molecular weight (Nitta

453 et al., 2003; Campbell et al., 2008). However, we have no ideas if such leakage or exchange of CSF 
454 and plasma component occurs via strand breaks and affects the infiltration of Gd-contrast agent in

455 the intact developing brain.

\section{Relevance to brain physiological dysfunctions}

457 Currently, researchers assume that disruption of BBB integrity, infiltration of immune cells,

458 and inflammatory cytokines via aberrant immune activity in the developing brain have a link to

459 various types of psychiatric disorders (Claudio, 1996; Perry et al., 1997; Lou et al., 1997; Bolton et

460 al., 1998; Davalos et al., 2012; Lepennetier et al., 2019; Montagne et al., 2020; Yang et al., 2020;

461 Mastorakos et al., 2021). Invasion of stimulated immune cells or inflammatory cytokines into the

462 brain parenchyma may disturb the neuronal function through excessive immune responses (Yirmiya

463 et al., 2015; Becher et al., 2017; Dietz et al., 2020; Segawa et al., 2021). The BBB TJ-disruption

464 could be a signature phenotype of psychiatric disorders in animals. A loss of claudin-5 in the nucleus

465 accumbens is shown associated with depressive-like behaviors, while loss of claudin-5 in the

466 hippocampus and mPFC is associated with schizophrenia-like behaviors (Menard et al., 2017;

467 Greene et al., 2018). Therefore, it was important to know the functional development of the barrier in 468 the brain to display which regions are permeable. Aberrant immunity in the vulnerable areas would

469 also lead to neurophysiological dysfunctions and disruption of functional connectivity. For instance,

470 activated microglia or released inflammatory cytokines in the prefrontal cortex and cerebellum

471 induce forms of plasticity of intrinsic excitability of various types of neurons (Schonewille et al.,

472 2010; Belmeguenai et al., 2010; Ohtsuki et al., 2012; Duan et al., 2018; Yamamoto et al., 2019;

473 Ohtsuki, 2020; Ohtsuki et al., 2020; Ozaki et al., 2021; Yamawaki et al., in revision), as well as of

474 excitatory and inhibitory synaptic transmission (Zhang et al., 2014; Duan et al., 2018; Yamamoto et

475 al., 2019; Zheng et al., 2021; Yamawaki et al., in revision). These modulations of both brain-wide

476 functional networks are associated with psychiatric diseases-like behaviors (Yamamoto et al., 2019;

477 Granja et al., 2021). One of the upcoming questions is if dysfunction of the vasculature system

478 suffices to the emergence of developmental disorders via peripheral immunity and if the timing of 
bioRxiv preprint doi: https://doi.org/10.1101/2021.09.21.461189; this version posted September 24, 2021. The copyright holder for this preprint (which was not certified by peer review) is the author/funder. All rights reserved. No reuse allowed without permission.

479 the maturation of CSF barrier determines the period for the emergence of developmental disorders.

480 Future comprehensive work would explain the relevance between CSF-flow dynamics in

481 developmental brains and brain dysfunctions.

482 


\section{Materials \& Methods}

484 Animal ethics statement. All procedures were performed following the guidelines of the Animal

485 Care and Use Committees and approved by the Ethical Committee of Kyoto University. All animal

486 handling and reporting comply with the ARRIVE guidelines. Mice were housed (4 animals at

487 maximum in each cage) and maintained under a 12-h light: 12-h dark cycle, at a constant

488 temperature and humidity (20-24 $\square, 35 \%-55 \%)$, with food and water available ad libitum. We

489 conducted all animal procedures for MRI experiments following the guidelines of animal

490 experiments at Kyoto University. The MRI experiments of this work were performed in the Division

491 for Small Animal MRI, Medical Research Support Center, Graduate School of Medicine, Kyoto

492 University, Japan.

493

494 Gd-reagent injection. For injection of Gd-contrast agent into the cisterna magna, C57BL/6 male

495 mice were fixed to the stereotaxic apparatus (NARISHIGE Group, Japan) under inhalation isoflurane

496 (2\% for induction: $0.8 \%$ for operation with $0.1-0.2 \%$ oxygen or air). After cutting off the scalp and

497 lesser posterior rectus capitis muscles of the back of the mouse with scissors and a surgical knife, we

498 made one tiny sting (with a $200 \mu \mathrm{m}$ diameter) by penetration using a 27 -gade needle, following

499 which the tip of the needle of a syringe (GASTIGHT® \#1705, Hamilton Co.) was inserted 3.6-3.9

$500 \mathrm{~mm}$ forward at a slow angle of $5^{\circ}$ negative. We infused a 35-38 $\mu$ undiluted Gd-contrast agent

501 (GadoSpin M, Miltenyi Biotec, USA) in 5-8 minutes. Less amount of injection did not achieve the

502 lateral ventricles. To monitor the entire CSF flow dynamics in the entire brain vasculatures, we

503 intentionally infused a bulk amount of Gd-contrast agent. Please note that this rate and duration of

504 Gd-contrast agent infusion would lead to reflux of subarachnoid CSF back into the ventricular CSF

505 compartments, indicating that the physiological direction of CSF-flow is not maintained initially

506 (Kress et al., 2014). The wound was sealed with Spongel (Astellas Pharma Inc.), after which the

507 animals were allowed to proceed with the MR imaging. The maximum time interval for the start of 
508 the initial MRI acquisition from the end of the operation was 9 minutes, and thus, we used this time

509 in Figure 2. Upon intravenous injection, GadoSpin M is rapidly distributed in the extracellular space.

510 According to the prescription of GadoSpin M, the Gd-contrast agent is excreted via glomerular

511 filtration (kidneys) within hours. We did not find any plasma protein complex during the MRI.

\section{MRI experiments.}

514 1. Animal preparations. Under general anesthesia with inhalation of $2.5 \%$ isoflurane in the air at 1

$515 \mathrm{~L} / \mathrm{min}$ through a face mask, mice were placed in a cradle in a prone position. The mouse head was

516 fixed using a tooth bar and surgical tapes. The animal's respiratory rate and rectal temperature were

517 continuously monitored via a pressure-sensitive respiration sensor and thermistor temperature probe,

518 respectively, and monitored using a dedicated system (Model 1025, MR-compatible Small Animal

519 Monitoring \& Gating System; SA Instruments, Inc., NY, USA) equipped with software (PC-SAM

520 V.5.12; SA Instruments). The body temperature was maintained by a flow of warm air using a heater

521 system (MR-compatible Small Animal Heating System, SA Instruments). The isoflurane

522 concentration was adjusted in the range of $0.6-1.2 \%$ to ensure a stable and reproducible depth of

523 anesthesia based on the respiration rate.

524 2. MRI acquisitions. All MRI measurements were conducted on a 7-Tesla preclinical scanner

525 (BioSpec 70/20 USR; Bruker BioSpin MRI GmbH, Ettlingen, Germany). quadrature transmit-

526 receive volume coil (inner diameter $35 \mathrm{~mm}$, T9988; Bruker BioSpin) was used to detect MR signals.

527 The MRI system was controlled with a dedicated operation software (ParaVision 5.1; Bruker

528 BioSpin).

529 2.1. 3D T1-weighted MRI. A series of 3D T1-weighted (T1W) images was acquired using a fast low

530 angle shot (FLASH) sequence with the following acquisition parameters: repetition time (TR), 30

$531 \mathrm{~ms}$; echo time (TE), 3.3ms; flip angle, $25^{\circ}$; field of view (FOV), $22.5 \times 15 \times 15 \mathrm{~mm}^{3}$, acquisition

532 matrix size, $144 \times 96 \times 96$; isotropic spatial resolution of $0.15625 \mathrm{~mm}$; coronal orientation (i.e., axial 
533 in mouse brain); without averaging; and scan time, 4 min 36 s. As a baseline image as Frame 1, a

534 non-contrast-enhanced image was also acquired before injecting the Gd-contrast agent. The FLASH

535 scan was repeated 26 times over 120 min with 4 min 36 s intervals as Frames 2 to 27.

536 2.2. 3D T2-weighted MRI. As an anatomical reference image, a 3D T2-weighted (T2W) image was

537 acquired using a rapid acquisition with relaxation enhancement (RARE) sequence. The acquisition

538 parameters were: TR, $1500 \mathrm{~ms}$; effective TE, $45 \mathrm{~ms}$, RARE factor, 16; fat suppression; flip back; and

539 scan time, 14 min 24 s. The other parameters were the same as the 3D T1W imaging.

540 3. Image processing. Using the acquired MR images, the following analyses were conducted. All

541 data were processed using FMRIB Software Library (FSL; the Analysis Group, FMRIB, Oxford, UK,

542 https://fsl.fmrib.ox.ac.uk/fsl/fslwiki) (Jenkinson et al., 2012) and ImageJ (Rasband, W.S., ImageJ, U.

543 S. National Institutes of Health, Bethesda, Maryland, USA, https://imagej.nih.gov/ij/, 1997-2018).

544 3.1. Pre-processing for analyzing the time course of contrast enhancement. In the analyses using

545 FSL, all images had their pixel dimensions scaled up in the NIfTI header by a factor of 10 to avoid

546 the scale-depended issue when using standard FSL software. Pixel values of the baseline image and

547 the series of contrast-enhanced images were converted to the absolute image intensity. The baseline

548 image was linearly (6 degrees of freedom) registered to the first image in the contrast-enhanced time

549 series data set using FSL's FLIRT (Jenkinson et al., 2002). These images were motion-corrected

550 using FSL's MCFLIRT (Jenkinson et al., 2002) and then a mean T1W image was generated by

551 taking the mean value across time on a pixel-by-pixel basis. The mean T1W image was linearly $(6$

552 degrees of freedom) registered to the corresponding anatomical (T2W) image and the transformation

553 matrix was stored. The transformation matrix was used for the registration of the time series T1W

554 images to the anatomical image. A T2W brain template image of C57Bl/6 mouse (Hikishima et al.,

555 2017), which is available from the Neuroimaging Informatics Tools and Resources Clearinghouse

556 (NITRC) website (https://www.nitrc.org/projects/tpm mouse), was used in the present study. The

557 template image was downsampled so as the spatial resolution to match our images. Then a 
558 rectangular region of interest (ROI), in which almost the minimum region surrounding the whole

559 brain was included, was extracted from the template image. The anatomical image of each mouse

560 was linearly (12 degrees of freedom) registered to the template brain and the generated

561 transformation matrix was applied to the motion-corrected and registered T1W data series. All the

562 processing for image registration was performed by using FSL's FLIRT.

563 3.2. Maximum intensity projection. To visualize the distribution of the Gd-contrast agent, maximum

564 intensity projection (MIP) images were generated from a 3D T1W time series data set. Using 3D

565 projection in ImageJ's routine, a total of 36 MIP images for each volume (i.e., each time point data)

566 was created through a total rotation angle of $360^{\circ}$ with an increment of $10^{\circ}$ and an axis of rotation

567 along the anterior-posterior direction. The resulting data set depicts $360^{\circ}$-rotation of the MIP image.

568 3.3. Data analyses and statistics. After preprocessing with FLIRT, we obtained the Gd-signals of the

569 regions of interest with the FSLeyes (https://fsl.fmrib.ox.ac.uk/fsl/fslwiki/FSLeyes). The time series

570 of the voxel intensities were taken from 4D NIFTI images of the lymphatic vessels, ventricles, and

571 parenchymas. The coordination of the C57Bl/6 mouse brain template space (Hikishima et al., 2017)

572 is followings (i.e., $\mathrm{x}, \mathrm{y}$, and $\mathrm{z}$ ):

573 (lymphatic vessels and ventricles)

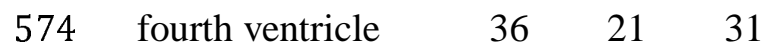

$\begin{array}{lllll}575 & \text { aqueduct } & 36 & 29 & 39\end{array}$

576 dorsal third ventricle_1 $36 \quad 46 \quad 42$

577 dorsal third ventricle_2 $36 \quad 57 \quad 39$

578 ventral third ventricle_1 $36 \quad 62 \quad 31$

579 ventral third ventricle_2 $36 \quad 64 \quad 23$

580 ventral third ventricle_3 $\quad 36 \quad 54 \quad 21$

581 olfactory artery_1 $36 \quad 80 \quad 26$

582 olfactory artery_2 $36 \quad 92 \quad 32$ 
583 rostral rhinal vein_1 $36 \quad 83 \quad 47$

584 rostral rhinal vein_2 $36 \quad 79 \quad 39$

585 rostral confluence of sinuses $\begin{array}{lll}36 & 76 \quad 52\end{array}$

$\begin{array}{llll}586 & \text { superior sagittal sinus } 36 \quad 62 \quad 53\end{array}$

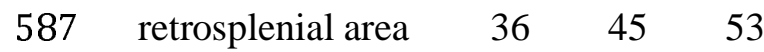

588 posterior cerebral artery, right22 $36 \quad 31$

589 posterior cerebral artery, left $\begin{array}{llll}50 & 36 & 31\end{array}$

590 caudal ventral lateral ventricle, right $14 \quad 45 \quad 30$

$\begin{array}{llll}591 & \text { caudal ventral lateral ventricle, left } & 58 & 45 \quad 30\end{array}$

592 posterior communicating artery, right29 $43 \quad 22$

593 posterior communicating artery, left $44 \quad 43 \quad 22$

594 rostral lateral ventricle, right $32 \quad 65 \quad 41$

595 rostral lateral ventricle, left $41 \quad 65 \quad 41$

596 deep cervical lymph node, right $\quad 30 \quad 11 \quad 12$

$\begin{array}{lllll}597 & \text { deep cervical lymph node, left } & 42 & 11 & 12\end{array}$

$\begin{array}{lllll}598 & \text { basal outflow, right } & 18 & 28 & 15\end{array}$

599 basal outflow, left $\quad 53 \quad 28 \quad 15$

600 rostral ventral lateral ventricle, right $30 \quad 61 \quad 35$

601 rostral ventral lateral ventricle, left $42 \quad 61 \quad 35$

602 nasopharynx, right $27 \quad 38 \quad 8$

603 nasopharynx, left $47 \quad 38 \quad 8$;

604 (parenchymas)

605 cerebellar cortex, posterior lobes $\quad 36 \quad 11 \quad 35$

$\begin{array}{llll}606 & \text { cerebellar cortex, anterior lobes } & 36 & 19\end{array} 45$

$\begin{array}{lllll}607 & \text { cerebellar cortex, middle lobes } & 36 & 10 & 43\end{array}$ 
608 cerebellar cortex, hemisphere, right $\quad 19 \quad 17 \quad 38$

609 cerebellar cortex, hemisphere, left $\quad 53 \quad 17 \quad 38$

610 cerebellar fastigial nucleus, right $\quad 30 \quad 21 \quad 34$

611 cerebellar fastigial nucleus, left $\quad 42 \quad 21 \quad 34$

$\begin{array}{lllll}612 & \text { cerebellar dentate nucleus, right } & 21 & 21 & 34\end{array}$

$\begin{array}{lllll}613 & \text { cerebellar dentate nucleus, left } & 51 & 21 & 34\end{array}$

$\begin{array}{lllll}614 & \text { spinal cord } & 36 & 2 & 17\end{array}$

615 periaqueductal gray $36 \quad 35 \quad 40$

$\begin{array}{lllll}616 & \text { dorsal raphe nucleus } & 36 & 36 & 36\end{array}$

$\begin{array}{lllll}617 & \text { superior colliculus } & 36 & 31 & 47\end{array}$

618 pons $\quad 36 \quad 32 \quad 31$

$\begin{array}{lllll}619 & \text { ventral tegmental area, right } & 32 & 44 & 26\end{array}$

620 ventral tegmental area, left $40 \quad 44 \quad 26$

621 orbitofrontal cortex, right $18 \quad 72 \quad 36$

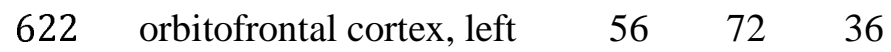

623 medial prefrontal cortex, right $\quad 33 \quad 70 \quad 42$

624 medial prefrontal cortex, left $40 \quad 70 \quad 42$

625 olfactory bulb, right $31 \quad 93 \quad 42$

626 olfactory bulb, left $41 \quad 93 \quad 42$

627 olfactory bulb, center $36 \quad 93 \quad 42$.

628 Due to the difference in the position and shape of lymphatic nodes, we adjusted the coordination to

629 the center of the deep cervical lymph node of each animal. Voxel intensities as Gd-signals were

630 normalized by both minimum and maximum intensity for each animal. Then, the average across

631 animals and standard error of measurement (SEM) were taken for each brain region. All data are

632 presented as mean \pm SEM. Data of P4-week, P8-9-week, and P12-week-old mice were collected 
633 from 7, 5, and 6 animals for each. We summed up the P8-9-week and P12-week-old mice data

634 together. One-sided Mann-Whitney $U$-tests (Cardillo, 2009) were used to compare data of

635 normalized Gd-signal amplitude and summed Gd signals between two independent groups (Figure 3,

636 4, and 6). Two-tailed Student's t-tests with unequal variances were used for the data of time to peak

637 and full-width of half maximum (FWHM) because two-sampled groups are considered from the

638 same distribution (Figure 5). We considered $\mathrm{p}<0.05$ as the significance level throughout the study.

639 All statistical analyses were performed using Matlab 2015.

640

641 4. MRA. Three-dimensional time-of-flight MR angiography (3D TOF-MRA) was performed with

642 the following acquisition parameters: pulse sequence, the gradient-echo sequence with a first-order

643 flow compensation in all logical gradient directions; TR, $100 \mathrm{~ms}$; TE, $4.63 \mathrm{~ms}$; flip angle, 45; FOV,

$64419.2 \times 12.8 \times 9.6 \mathrm{~mm}^{3}$; acquisition matrix size, $192 \times 128 \times 96$; isotropic spatial resolution of $100 \mu \mathrm{m}$; the

645 number of averages, 4 ; and scan time, $1 \mathrm{~h} 22 \mathrm{~min}$. 
648 Acknowledgments: We would like to present our deep appreciation to Prof. Shu Narumiya, Drs.

649 Takeshi Sakurai, and Kosuke Tanigaki for invaluable comments and supports on the research. We

650 thank Rie Toyoda, and Konomi Nimura for the validation of data analyses and image drawings. MRI

651 was performed at the Medical Research Support Center, Graduate School of Medicine, Kyoto

652 University, which was supported by Platform for Drug Discovery, Informatics, and Structural Life

653 Science from the Ministry of Education, Culture, Sports, Science and Technology, Japan. We also

654 appreciate Sumitomo Dainippon Pharma Co., Ltd., ONO PHARMACEUTICAL CO., LTD.,

655 Mitsubishi Tanabe Pharma Corporation., and KYORIN Pharmaceutical Co., Ltd. as the sponsors for

656 the Department of Drug Discovery Medicine.

658 Competing interests: The author declares no competing interests. The authors declare that the

659 research was conducted without any commercial or financial relationships that could be construed as

660 a potential conflict of interest.

661

\section{Author Contributions}

663 G.O., H.I., Y.Y., and S.M. conducted the experiments. G.O., Y.W., Md S.A.P., and Y.Y. analyzed

664 data. G.O. and H.I. designed the experiments. G.O., Y.W., H.I., Y.Y., Md S.A.P., and S.M. wrote the

665 manuscript. This work was supported by grants from the Naito Foundation, the Mitsubishi

666 Foundation, and the Takeda Science Foundation (all to G.O.), and by JSPS WISE program "The

667 Graduate Program for Medical Innovation" (to Y.Y.). The funders had no role in study design,

668 decision to publish, or preparation of the manuscript. 


\section{References}

671 Absinta M, Ha SK, Nair G, Sati P, Luciano NJ, Palisoc M, Louveau A, Zaghloul KA, Pittaluga S, 672 Kipnis J, Reich DS. (2017). Human and nonhuman primate meninges harbor lymphatic vessels that 673 can be visualized noninvasively by MRI. eLife 6:e29738, doi: 10.7554/eLife.29738.

Ahn JH, Cho H, Kim JH, Kim SH, Ham JS, Park I, Suh SH, Hong SP, Song JH, Hong YK, Jeong Y, Park SH, Koh GY. (2019). Meningeal lymphatic vessels at the skull base drain cerebrospinal fluid.

Akaishi T, Takahashi T, Nakashima I, Abe M, Aoki M, Ishii T. (2020). Osmotic pressure of serum and cerebrospinal fluid in patients with suspected neurological conditions. Neural Regen Res 15, 944-947. doi: 10.4103/1673-5374.268906.

Aspelund A, Antila S, Proulx ST, Karlsen TV, Karaman S, Detmar M, Wiig H, Alitalo K. (2015). A dural lymphatic vascular system that drains brain interstitial fluid and macromolecules. J Exp Med. 212, 991-999, doi:10.1084/jem.20142290.

Aydin K, Terzibasioglu E, Sencer S, Sencer A, Suoglu Y, Karasu A, Kiris T, Turantan MI. (2008). Localization of cerebrospinal fluid leaks by gadolinium-enhanced magnetic resonance cisternography: a 5-year single-center experience. Neurosurgery 62, 584-589. doi: 10.1227/01.neu.0000317306.39203.24.

Bauer H, Sonnleitner U, Lametschwandtner A, Steiner M, Adam H, Bauer HC. (1995). Ontogenic expression of the erythroid-type glucose transporter (Glut 1) in the telencephalon of the mouse: correlation to the tightening of the blood-brain barrier. Brain Res Dev Brain Res 86, 317-325. doi: 10.1016/0165-3806(95)00044-e.

Bauer HC, Krizbai IA, Bauer H, Traweger A. (2014). "You Shall Not Pass"-tight junctions of the blood brain barrier. Front Neurosci 8:392. doi: 10.3389/fnins.2014.00392.

Becher B, Spath S, Goverman J. (2017). Cytokine networks in neuroinflammation. Nat Rev Immunol 17, 49-59. doi: 10.1038/nri.2016.123.

Belmeguenai A, Hosy E, Bengtsson F, Pedroarena CM, Piochon C, Teuling E, He Q, Ohtsuki G, De Jeu MT, Elgersma Y, De Zeeuw CI, Jörntell H, Hansel C. (2010). Intrinsic plasticity complements long-term potentiation in parallel fiber input gain control in cerebellar Purkinje cells. J Neurosci 30, 13630-13643. doi: 10.1523/JNEUROSCI.3226-10.2010.

Berndt P, Winkler L, Cording J, Breitkreuz-Korff O, Rex A, Dithmer S, Rausch V, Blasig R, Richter M, Sporbert A, Wolburg H, Blasig IE, Haseloff RF. (2019). Tight junction proteins at the bloodbrain barrier: far more than claudin-5. Cell Mol Life Sci 76, 1987-2002. doi: 10.1007/s00018-01903030-7.

Bolton SJ, Anthony DC, Perry VH. (1998) Loss of the tight junction proteins occludin and zonula occludens-1 from cerebral vascular endothelium during neutrophil-induced blood-brain barrier breakdown in vivo. Neuroscience 86, 1245-1257. doi: 10.1016/s0306-4522(98)00058-x.

Brown PD, Davies SL, Speake T, Millar ID (2004). Molecular mechanisms of cerebrospinal fluid production. Neuroscience 129, 957-970. doi: 10.1016/j.neuroscience.2004.07.003. 
Butt AM, Jones HC, Abbott NJ. (1990). Electrical resistance across the blood-brain barrier in anaesthetized rats: a developmental study. J Physiol 429, 47-62. doi: 10.1113/jphysiol.1990.sp018243.

Campbell M, Kiang AS, Kenna PF, Kerskens C, Blau C, O'Dwyer L, Tivnan A, Kelly JA, Brankin B, Farrar GJ, Humphries P. (2008). RNAi-mediated reversible opening of the blood-brain barrier. J Gene Med 10, 930-947. doi: 10.1002/jgm.1211.

Cardillo G. (2009). MWWTEST: Mann-Whitney-Wilcoxon non parametric test for two unpaired samples. http://www.mathworks.com/matlabcentral/fileexchange/25830.

Claudio L. (1996) Ultrastructural features of the blood-brain barrier in biopsy tissue from Alzheimer's disease patients. Acta Neuropathol 91, 6-14. doi: 10.1007/s004010050386.

Coelho-Santos V, Shih AY. (2020). Postnatal development of cerebrovascular structure and the neurogliovascular unit. Wiley Interdiscip Rev Dev Biol 9:e363. doi: 10.1002/wdev.363.

Cserr HF (1971). Physiology of the choroid plexus. Physiol Rev 51, 273-311. doi: 10.1152/physrev.1971.51.2.273.

Da Mesquita S, Louveau A, Vaccari A, Smirnov I, Cornelison RC, Kingsmore KM, Contarino C, Onengut-Gumuscu S, Farber E, Raper D, Viar KE, Powell RD, Baker W, Dabhi N, Bai R, Cao R, Hu S, Rich SS, Munson JM, Lopes MB, Overall CC, Acton ST, Kipnis J. (2018a). Functional aspects of meningeal lymphatics in ageing and Alzheimer's disease. Nature 560, 185-191. doi: 10.1038/s41586-018-0368-8.

Da Mesquita S, Fu Z, Kipnis J. (2018b). The Meningeal Lymphatic System: A New Player in Neurophysiology. Neuron 100, 375-388, doi:10.1016/j.neuron.2018.09.022.

Davalos, D., Ryu, J.K., Merlini, M., Baeten, K.M., Le Moan, N., Petersen, M.A., Deerinck, T.J., Smirnoff, D.S., Bedard, C., Hakozaki, H., Gonias Murray, S., Ling, J.B., Lassmann, H., Degen, J.L., Ellisman, M.H., Akassoglou, K. (2012) Fibrinogen-induced perivascular microglial clustering is required for the development of axonal damage in neuroinflammation. Nat Commun 3:1227. doi: $10.1038 /$ ncomms 2230 .

Dietz, A.G., Goldman, S.A., Nedergaard, M. (2020) Glial cells in schizophrenia: a unified hypothesis. Lancet Psychiatry 7, 272-281. doi: 10.1016/S2215-0366(19)30302-5.

Duan L, Zhang XD, Miao WY, Sun YJ, Xiong G, Wu Q, Li G, Yang P, Yu H, Li H, Wang Y, Zhang M, Hu LY, Tong X, Zhou WH, Yu X. (2018). PDGFR $\beta$ Cells Rapidly Relay Inflammatory Signal from the Circulatory System to Neurons via Chemokine CCL2. Neuron 100, 183-200.e8. doi: 10.1016/j.neuron.2018.08.030.

Fallier-Becker P, Vollmer JP, Bauer HC, Noell S, Wolburg H, Mack AF. (2014). Onset of aquaporin-4 expression in the developing mouse brain. Int J Dev Neurosci 36, 81-89. doi: 10.1016/j.ijdevneu.2014.06.001. 
Junior V, Weyrich AS, Rondina MT, Zimmerman GA, de Castro-Faria-Neto HC. (2021).

Inflammatory, synaptic, motor and behavioral alterations induced by gestational sepsis on the offspring at different stages of life. J Neuroinflammation 18:60. doi: 10.1186/s12974-021-02106-1.

Greene C, Kealy J, Humphries MM, Gong Y, Hou J, Hudson N, Cassidy LM, Martiniano R, Shashi V, Hooper SR, Grant GA, Kenna PF, Norris K, Callaghan CK, Islam MD, O'Mara SM, Najda Z,

Greene C, Hanley N, Campbell M. (2019). Claudin-5: gatekeeper of neurological function. Fluids Barriers CNS 16:3. doi: 10.1186/s12987-019-0123-z.

Harb R, Whiteus C, Freitas C, Grutzendler J. (2013). In vivo imaging of cerebral microvascular plasticity from birth to death. J Cereb Blood Flow Metab 33, 146-156. doi: 10.1038/jcbfm.2012.152.

Hikishima K, Komaki Y, Seki F, Ohnishi Y, Okano HJ, Okano H. (2017). In vivo microscopic voxel-based morphometry with a brain template to characterize strain-specific structures in the mouse brain. Sci Rep 7:85. doi: 10.1038/s41598-017-00148-1.

Huber JD, Egleton RD, Davis TP. (2001). Molecular physiology and pathophysiology of tight junctions in the blood-brain barrier. Trends Neurosci 24, 719-725. doi: 10.1016/s01662236(00)02004-X.

Iliff JJ, Wang M, Liao Y, Plogg BA, Peng W, Gundersen GA, Benveniste H, Vates GE, Deane R, Goldman SA, Nagelhus EA, Nedergaard M. (2012). A paravascular pathway facilitates CSF flow through the brain parenchyma and the clearance of interstitial solutes, including amyloid $\beta$. Sci Transl Med 4:147ra111. doi: 10.1126/scitranslmed.3003748.

Iliff JJ, Lee H, Yu M, Feng T, Logan J, Nedergaard M, Benveniste H. (2013). Brain-wide pathway for waste clearance captured by contrast-enhanced MRI. J Clin Invest 123, 1299-1309. doi: 10.1172/JCI67677.

Jenkinson M, Bannister P, Brady M, Smith S. (2002). Improved optimization for the robust and accurate linear registration and motion correction of brain images. Neuroimage 17, 825-841. doi: 10.1016/s1053-8119(02)91132-8.

Jenkinson M, Beckmann CF, Behrens TE, Woolrich MW, Smith SM. (2012). FSL. Neuroimage 62, 782-790. doi: 10.1016/j.neuroimage.2011.09.015. physiological brain activity - Glymphatic pulsation mechanisms? J Cereb Blood Flow Metab 36, 1033-1045. doi: 10.1177/0271678X15622047. 
818 Lepennetier G, Hracsko Z, Unger M, Van Griensven M, Grummel V, Krumbholz M, Berthele A, 819 Hemmer B, Kowarik MC. (2019). Cytokine and immune cell profiling in the cerebrospinal fluid of 820 patients with neuro-inflammatory diseases. J Neuroinflammation 16:219. doi: 10.1186/s12974-019821 1601-6.

822

823

824

825

826

827

828

829

830

831

832

833

834

835

836

837

838

839

840

841

842

843

844

845

846

847

848

849

850

851

852

853

854

855

856

857

858

859

860

861

862

863

864

865

866

867
Liu G, Mestre H, Sweeney AM, Sun Q, Weikop P, Du T, Nedergaard M. (2020). Direct

Measurement of Cerebrospinal Fluid Production in Mice. Cell Rep 33:108524. doi:

10.1016/j.celrep.2020.108524.

Lou J, Chofflon M, Juillard C, Donati Y, Mili N, Siegrist CA, Grau GE. (1997) Brain microvascular endothelial cells and leukocytes derived from patients with multiple sclerosis exhibit increased adhesion capacity. Neuroreport 8, 629-633. doi: 10.1097/00001756-199702100-00010.

Louveau A, Smirnov I, Keyes TJ, Eccles JD, Rouhani SJ, Peske JD, Derecki NC, Castle D, Mandell JW, Lee KS, Harris TH, Kipnis J. (2015). Structural and functional features of central nervous system lymphatic vessels. Nature 523, 337-341, doi:10.1038/nature14432.

Louveau A, Plog B.A., Antila S, Alitalo K, Nedergaard M, Kipnis J. (2017). Understanding the functions and relationships of the glymphatic system and meningeal lymphatics. J Clin Invest 127 , 3210-3219. doi: 10.1172/JCI90603.

Louveau A, Herz J, Alme MN, Salvador AF, Dong MQ, Viar KE, Herod SG, Knopp J, Setliff JC, Lupi AL, Da Mesquita S, Frost EL, Gaultier A, Harris TH, Cao R, Hu S, Lukens JR, Smirnov I, Overall CC, Oliver G, Kipnis J. (2018). CNS lymphatic drainage and neuroinflammation are regulated by meningeal lymphatic vasculature. Nat Neurosci 21, 1380-1391, doi:10.1038/s41593018-0227-9.

Marín-Padilla M. (2012). The human brain intracerebral microvascular system: development and structure. Front Neuroanat 6:38. doi: 10.3389/fnana.2012.00038.

Mastorakos P, Mihelson N, Luby M, Burks SR, Johnson K, Hsia AW, Witko J, Frank JA, Latour L, McGavern DB. (2021) Temporally distinct myeloid cell responses mediate damage and repair after cerebrovascular injury. Nat Neurosci 24, 245-258. doi: 10.1038/s41593-020-00773-6.

Menard C, Pfau ML, Hodes GE, Kana V, Wang VX, Bouchard S, Takahashi A, Flanigan ME, Aleyasin H, LeClair KB, Janssen WG, Labonté B, Parise EM, Lorsch ZS, Golden SA, Heshmati M, Tamminga C, Turecki G, Campbell M, Fayad ZA, Tang CY, Merad M, Russo SJ. (2017). Social stress induces neurovascular pathology promoting depression. Nat Neurosci 20, 1752-1760. doi: 10.1038/s41593-017-0010-3.

Montagne A, Nation DA, Sagare AP, Barisano G, Sweeney MD, Chakhoyan A, Pachicano M, Joe E, Nelson AR, D'Orazio LM, Buennagel DP, Harrington MG, Benzinger TLS, Fagan AM, Ringman JM, Schneider LS, Morris JC, Reiman EM, Caselli RJ, Chui HC, Tcw J, Chen Y, Pa J, Conti PS, Law M, Toga AW, Zlokovic BV. (2020). APOE4 leads to blood-brain barrier dysfunction predicting cognitive decline. Nature 581, 71-76. doi: 10.1038/s41586-020-2247-3.

Nico B, Ribatti D, Frigeri A, Nicchia GP, Corsi P, Svelto M, Roncali L. (2002). Aquaporin-4 expression during development of the cerebellum. Cerebellum 1, 207-212. doi: $10.1080 / 14734220260418439$. 
868 Nielsen S, Nagelhus EA, Amiry-Moghaddam M, Bourque C, Agre P, Ottersen OP. (1997).

869 Specialized membrane domains for water transport in glial cells: high-resolution immunogold

870 cytochemistry of aquaporin-4 in rat brain. J Neurosci 17, 171-180. doi: 10.1523/JNEUROSCI.17-01-

87100171.1997.

872

873

874

875

876

877

878

879

880

881

882

883

884

885

886

887

888

889

890

891

892

893

894

895

896

897

898

899

900

901

902

903

904

905

906

907

908

909

910

911

912

913

914

915

916

917

Nitta T, Hata M, Gotoh S, Seo Y, Sasaki H, Hashimoto N, Furuse M, Tsukita S. (2003). Size-

selective loosening of the blood-brain barrier in claudin-5-deficient mice. J Cell Biol 161, 653-660.

doi: $10.1083 /$ jcb.200302070.

Ohtsuki G, Piochon C, Adelman JP, Hansel C. (2012). SK2 channel modulation contributes to compartment-specific dendritic plasticity in cerebellar Purkinje cells. Neuron 75, 108-120. doi: 10.1016/j.neuron.2012.05.025.

Ohtsuki G. (2020). Modification of Synaptic-Input Clustering by Intrinsic Excitability Plasticity on Cerebellar Purkinje Cell Dendrites. J Neurosci 40, 267-282. doi: 10.1523/JNEUROSCI.321118.2019.

Ohtsuki G, Shishikura M, Ozaki A. (2020). Synergistic excitability plasticity in cerebellar functioning. FEBS J 287, 4557-4593. doi: 10.1111/febs.15355.

Ozaki A, Yamawaki Y, Ohtsuki G. (2021). Psychosis symptoms following aberrant immunity in the brain. Neural Regen Res 16, 512-513. doi: 10.4103/1673-5374.293148.

Pardridge WM. (2016). CSF, blood-brain barrier, and brain drug delivery. Expert Opin Drug Deliv 13, 963-975. doi: 10.1517/17425247.2016.1171315.

Perry VH, Anthony DC, Bolton SJ, Brown HC. (1997). The blood-brain barrier and the inflammatory response. Mol Med Today 3, 335-341, doi:10.1016/S1357-4310(97)01077-0.

Praetorius J. (2007). Water and solute secretion by the choroid plexus. Pflugers Arch 454, 1-18. doi: 10.1007/s00424-006-0170-6.

Ringstad G, Eide PK. (2020). Cerebrospinal fluid tracer efflux to parasagittal dura in humans. Nat Commun 11:354. doi: 10.1038/s41467-019-14195-x.

Risau W, Wolburg H. (1990). Development of the blood-brain barrier. Trends Neurosci 13, 174-178. doi: 10.1016/0166-2236(90)90043-a.

Risau W. (1997). Mechanisms of angiogenesis. Nature 386, 671-674, doi:10.1038/386671a0.

Rustenhoven J, Drieu A, Mamuladze T, de Lima KA, Dykstra T, Wall M, Papadopoulos Z, Kanamori M, Salvador AF, Baker W, Lemieux M, Da Mesquita S, Cugurra A, Fitzpatrick J, Sviben S, Kossina R, Bayguinov P, Townsend RR, Zhang Q, Erdmann-Gilmore P, Smirnov I, Lopes MB, Herz J, Kipnis J. (2021). Functional characterization of the dural sinuses as a neuroimmune interface. Cell 184, 1000-1016.e27. doi: 10.1016/j.cell.2020.12.040.

Stanton EH, Persson NDÅ, Gomolka RS, Lilius T, Sigurðsson B, Lee H, Xavier ALR, Benveniste H, Nedergaard M, Mori Y. (2021). Mapping of CSF transport using high spatiotemporal resolution dynamic contrast-enhanced MRI in mice: Effect of anesthesia. Magn Reson Med 85, 3326-3342. doi: 10.1002/mrm.28645. 
Schonewille, M., Belmeguenai, A., Koekkoek, S.K., Houtman, S.H., Boele, H.J., van Beugen, B.J., Gao, Z., Badura, A., Ohtsuki, G., Amerika, W.E., Hosy, E., Hoebeek, F.E., Elgersma, Y., Hansel, C. De Zeeuw, C.I. (2010). Purkinje cell-specific knockout of the protein phosphatase PP2B impairs potentiation and cerebellar motor learning. Neuron 67, 618-628. doi: 10.1016/j.neuron.2010.07.009.

Segawa K, Blumenthal Y, Yamawaki Y, Ohtsuki G. (2021). A Destruction Model of the Vascular and Lymphatic Systems in the Emergence of Psychiatric Symptoms. Biology (Basel). 10:34. doi: 10.3390/biology10010034.

Sweeney MD, Kisler K, Montagne A, Toga AW, Zlokovic BV. (2018). The role of brain vasculature in neurodegenerative disorders. Nat Neurosci 21, 1318-1331. doi: 10.1038/s41593-018-0234-X.

Varadarajan S, Stephenson RE, Miller AL. (2019). Multiscale dynamics of tight junction remodeling. J Cell Sci 132:jcs229286. doi: 10.1242/jcs.229286.

Yagi Y, Ohkubo T, Kawaji H, Machida A, Miyata H, Goda S, Roy S, Hayashizaki Y, Suzuki H, Yokota T (2017). Next-generation sequencing-based small RNA profiling of cerebrospinal fluid exosomes. Neurosci Lett 636, 48-57. doi: 10.1016/j.neulet.2016.10.042.

Yamamoto M, Kim M, Imai H, Itakura Y, Ohtsuki G. (2019). Microglia-Triggered Plasticity of Intrinsic Excitability Modulates Psychomotor Behaviors in Acute Cerebellar Inflammation.

Cell Rep 28, 2923-2938.e8. doi: 10.1016/j.celrep.2019.07.078.

Yamawaki Y, Wada Y, Ohtsuki G. in revision: Microglia-triggered hypoexcitability plasticity of pyramidal neurons in the rat medial prefrontal cortex.

Yang AC, Stevens MY, Chen MB, Lee DP, Stähli D, Gate D, Contrepois K, Chen W, Iram T, Zhang L, Vest RT, Chaney A, Lehallier B, Olsson N, du Bois H, Hsieh R, Cropper HC, Berdnik D, Li L, Wang EY, Traber GM, Bertozzi CR, Luo J, Snyder MP, Elias JE, Quake SR, James ML, WyssCoray T. (2020). Physiological blood-brain transport is impaired with age by a shift in transcytosis. Nature 583, 425-430. doi: 10.1038/s41586-020-2453-z.

Yirmiya R, Rimmerman N, Reshef R. (2015). Depression as a microglial disease. Trends Neurosci 38, 637-658. doi: 10.1016/j.tins.2015.08.001.

Zhang J, Miller MI, Plachez C, Richards LJ, Yarowsky P, van Zijl P, Mori S. (2005). Mapping postnatal mouse brain development with diffusion tensor microimaging. Neuroimage 26, 1042-1051. doi: 10.1016/j.neuroimage.2005.03.009.

Zhang J, Malik A, Choi HB, Ko RW, Dissing-Olesen L, MacVicar BA. (2014). Microglial CR3 activation triggers long-term synaptic depression in the hippocampus via NADPH oxidase. Neuron 82, 195-207. doi: 10.1016/j.neuron.2014.01.043.

Zheng ZH, Tu JL, Li XH, Hua Q, Liu WZ, Liu Y, Pan BX, Hu P, Zhang WH. (2021).

Neuroinflammation induces anxiety- and depressive-like behavior by modulating neuronal plasticity in the basolateral amygdala. Brain Behav Immun 91, 505-518. doi: 10.1016/j.bbi.2020.11.007. 


\section{Video S1, Related to Figure 1B.}

968 A representative movie of the initial frame of Gd-contrast images of the postnatal 4 weeks mouse.

969 The movies were made from rotated series T1-images (3D maximum intensity projection images)

970 with every 20-degree difference.

971

\section{Video S2, Related to Figure 1C.}

973 A representative movie of the initial frame of Gd-contrast images of the postnatal 9 weeks mouse.

974 The movies were made from rotated series T1-images (3D maximum intensity projection images)

975 with every 20-degree difference. 